\title{
Article \\ The Copper-microRNA Pathway Is Integrated with Developmental and Environmental Stress Responses in Arabidopsis thaliana
}

\author{
Ana Perea-García ${ }^{1}$, Amparo Andrés-Bordería ${ }^{1,+}{ }^{\dagger}$ Peter Huijser ${ }^{2}$ and Lola Peñarrubia ${ }^{1, *}$ \\ 1 Departament de Bioquímica i Biologia Molecular and Institut Universitari de Biotecnologia i \\ Biomedicina (BIOTECMED), Universitat de València, 46100 Burjassot, Valencia, Spain; \\ ana.perea@uv.es (A.P.-G.); dandres@cipf.es (A.A.-B.) \\ 2 Department of Comparative Development and Genetics, Max Planck Institute for Plant Breeding Research, \\ Carl-von-Linné-Weg 10, 50829 Cologne, Germany; huijser@mpipz.mpg.de \\ * Correspondence: penarrub@uv.es; Tel.: +34-963-543-013 \\ + Present address: Unit of Rare Neurodegenerative Diseases, Centro de Investigación Príncipe Felipe (CIPF), \\ 46012 Valencia, Spain.
}

check for updates

Citation: Perea-García, A.; AndrésBordería, A.; Huijser, P.; Peñarrubia, L. The Copper-microRNA Pathway Is Integrated with Developmental and Environmental Stress Responses in Arabidopsis thaliana. Int. J. Mol. Sci. 2021, 22, 9547. https://doi.org/ $10.3390 /$ ijms 22179547

Academic Editors: Giorgio Gambino and Chiara Pagliarani

Received: 20 July 2021

Accepted: 23 August 2021

Published: 2 September 2021

Publisher's Note: MDPI stays neutral with regard to jurisdictional claims in published maps and institutional affiliations.

Copyright: (C) 2021 by the authors Licensee MDPI, Basel, Switzerland. This article is an open access article distributed under the terms and conditions of the Creative Commons Attribution (CC BY) license (https:// creativecommons.org/licenses/by/ $4.0 /)$

\begin{abstract}
As an essential nutrient, copper $(\mathrm{Cu})$ scarcity causes a decrease in agricultural production. $\mathrm{Cu}$ deficiency responses include the induction of several microRNAs, known as $\mathrm{Cu}$-miRNAs, which are responsible for degrading mRNAs from abundant and dispensable cuproproteins to economize copper when scarce. Cu-miRNAs, such as miR398 and miR408 are conserved, as well as the signal transduction pathway to induce them under $\mathrm{Cu}$ deficiency. The Arabidopsis thaliana SQUAMOSAPROMOTER BINDING PROTEIN-LIKE (SPL) family member SPL7 binds to the cis-regulatory motifs present in the promoter regions of genes expressed under $\mathrm{Cu}$ deficiency, including $\mathrm{Cu}$ miRNAs. The expression of several other SPL transcription factor family members is regulated by miR156. This regulatory miR156-SPL module plays a crucial role in developmental phase transitions while integrating internal and external cues. Here, we show that $\mathrm{Cu}$ deficiency also affects miR156 expression and that SPL3 overexpressing plants, resistant to miR156 regulation, show a severe decrease in SPL7-mediated Cu deficiency responses. These include the expression of $\mathrm{Cu}$-miRNAs and their targets and is probably due to competition between SPL7 and miR156-regulated SPL3 in binding to cis-regulatory elements in $\mathrm{Cu}$-miRNA promoters. Thus, the conserved SPL7-mediated $\mathrm{Cu}$-miRNA pathway could generally be affected by the miR156-SPL module, thereby underscoring the integration of the Cu-miRNA pathway with developmental and environmental stress responses in Arabidopsis thaliana.
\end{abstract}

Keywords: Arabidopsis thaliana; copper homeostasis; copper-microRNAs; development; SPL; stress

\section{Introduction}

The deficiency of essential nutrients, such as copper $(\mathrm{Cu})$, causes a decrease in agricultural productivity and crop performance. Copper participates as a cofactor in multiple plant physiological processes and the main symptoms produced by its deficiency affect young leaves and reproductive organs, reducing plant fertility and grain/seed yield [1]. While copper redox properties are involved in its essential functions, they can also produce hazardous reactive oxygen species (ROS). To accomplish copper requirements while avoiding toxicity requires a fine modulation of homeostatic networks for copper distribution [2-5]. In Chlamydomonas reinhardtii, $\mathrm{Cu}$ deficiency responses were shown to be driven by the master transcription factor Copper Response Regulator 1 (CRR1) [6,7]. Remarkably, given the evolutionary distance, its closest homologue in Arabidopsis, SPL7, turned out to be a master regulator of $\mathrm{Cu}$ deficiency responses too [8,9]. Both, CRR1 and SPL7 are members of the SQUAMOSA-PROMOTER BINDING PROTEIN-LIKE (SPL) family of transcription factors (TFs). 
In Arabidopsis thaliana, the SPL TFs are mainly involved in the control of developmental phase transitions, and associated with reproduction in particular [10]. The SPL family members share a conserved DNA binding domain, denoted as SBP-domain, and have been exclusively found in the green plant lineage [11]. The 16 members of the $A$. thaliana SPL family can be grouped in two subfamilies based on their sizes and similarities [12,13]. Large SPLs include SPL1, SPL7, SPL12, SPL14 and SPL16, whereas the remaining 11 SPLs are grouped as small SPLs [13]. With the exception of SPL8, the small SPLS also share a functional miRNA response element (MRE) downstream of the conserved SBP box that is complementary to miR156 and the closely related miR157 [14-17]. Hereafter, these SPLs will be denoted as MRE-SPLs since they are targeted post-transcriptionally by miR156 and miR157. Although miR156 and miR157 are both abundantly expressed before and less during the vegetative and reproductive phase transitions [15], genetic analysis showed that miR156 plays a more important role than miR157 in the timing of these phase transitions [18].

Whereas the floral transition involves the reduction of miR156/157 expression, another miRNA, miR172, becomes induced and promotes flowering through the posttranscriptional regulation of different AP2-like TFs [19,20]. Since the levels of miR156 decline as the plant ages [16,21,22], a subsequent gradual increase in the expression of miR156-targeted MRE-SPLs is observed. This process constitutes a regulatory module (miR156-SPL) for proper plant life cycle progression [16,22-28]. Constitutive overexpression of miR156 results in the delay of the juvenile-to-adult phase transition and mutations that render its MRE-SPL targets insensitive to miR156 have the opposite effect. For instance, the absence of a functional MRE in a constitutive promoter-driven SPL3 transgene has allowed the miR156/157-independent expression of the SPL3 protein in transgenic plants. As a consequence, these plants showed a shortened juvenile phase and obtained an early flowering phenotype $[16,17]$. This fact suggests that vegetative phase change in higher plants is primarily controlled by the miR156-SPL module. Furthermore, the expression of several miR156 genes has been found to become induced under various stress conditions, and the decrease in miR156 expression when conditions normalized has been associated with preparing for flowering, denoting that the miR156-SPL module coordinates development while integrating multi-stress responses $[29,30]$.

Transcription factor families generally expand with increasing organism complexity, consistent with a need for refined control of specific subsets of target genes. The DNA-binding recognition motif for SBP-domain TFs contains a core motif of only four nucleotides, GTAC [31,32]. The large number of members recognizing this short and highly abundant motif in the genome raises the possibility of competitive binding and thereby interfering with specificity in target gene regulation [33]. It is conceivable that several SPLs overlap in their biological functions and in their ability to compensate for the loss of other SPL functions $[13,16,27]$. Whether or not different SPL members may compete for binding to GTAC containing response elements in target promoters remains unsolved. Outside the conserved SBP domain, the 16 proteins of the SPL family show limited amino acid conservation, probably reflecting the specific roles attained by the different SPL proteins [27]. Among the large SPLs, the specific and unique role of SPL7 in Cu deficiency responses seems unquestioned. Function of the paralogous SPL1 and SPL12 genes could not be linked to the copper response [34], but rather seem to be implicated in thermotolerance [35], whereas spl14 mutants showed altered plant architecture [36].

The GTAC motifs bound by CRR1/SPL7 to regulate genes in response to $\mathrm{Cu}$ deficiency are known as Copper Response Elements (CuREs) [7,37,38]. Cu deficiency responses include the induction of several microRNAs (denoted as $\mathrm{Cu}$-miRNAs) that target cuproproteins. These Cu-miRNAs consist of miR397, miR398, miR408 and miR857 [37,39,40]. miR398 is responsible for degrading the mRNAs of genes (CSD1, CSD2) coding for $\mathrm{Cu}$ and zinc (Zn) superoxide dismutase $(\mathrm{Cu} / \mathrm{ZnSOD})$, the $\mathrm{Cu}$ chaperone $\mathrm{CCS}$ and for a subunit of the mitochondrial cytochrome $c$ oxidase, COX5b-1 [41-43]. Thus, one of the SPL7 functions in order to reserve copper for more essential processes is to replace $\mathrm{Cu}$-ZnSOD with iron superoxide dismutase (FeSOD), encoded by FSD1, [8,37,44]. miR398 is one of the most 
reported miRNAs to participate in abiotic and biotic stress regulatory networks. Copper, phosphate and water deficiencies, oxidative, salt and abscisic acid stresses, UV light and plant pathogens are just a few examples [45]. Accordingly, putative stress-responsive cis-elements were found in miR398 promoters [46]. Furthermore, CSD2 mRNA levels were not correlated with miR398 levels under certain stress conditions, suggesting the existence of miR398-dependent and independent regulatory mechanisms for CSD2 expression [46]. Due to the role of SODs as ROS scavengers, an important role of miR398 in oxidative stress resistance and plant survival has been postulated [47,48]. miR398 expression, as well as its targets, suffer a diurnal oscillation at the transcriptional level [49]. These data indicate that the spatiotemporal patterns of $\mathrm{Cu}$-miRNA expression may have an important role in the response to nutrient deficiency and add another layer of complexity to the study of their function.

miR408 targets transcripts of genes encoding abundant cuproproteins that belong to the phytocyanin family, such as plantacyanin, and several laccases involved in the oxidative polymerization of lignin [50-53]. The miR408 transcript levels respond to different abiotic stresses and elevated miR408 levels contribute to improved tolerance to salinity, cold and oxidative stress, but enhanced sensitivity to drought, osmotic stress and Fe deficiency $[53,54]$. Constitutive expression of miR408 results in enhanced vegetative growth, which led to suggestions of role as a modulator of development [55-57]. miR408 is among the most conserved miRNA families in land plants, while miR397 and miR398 are conserved in all angiosperms [58-60].

It is believed that $\mathrm{Cu}$-miRNAs eliminate the expression of particular cuproproteins and make the scarce copper available to essential cuproproteins of the organelle electron transport chains, such as plastocyanin and cytochrome $c$ oxidase [61]. However, little is known about how the function of components upstream in the $\mathrm{Cu}$-miRNA pathway, such as SPL7, is modulated to fine-tune this pathway according to developmental or stress signaling. The MRE-SPLs do not share conserved functional domains with SPL7 outside the DNA-binding domain which includes a nuclear localization signal [31]. However, both MRE-SPLs and SPL7 do recognize the same GTAC core element. Therefore, when co-expressed, some degree of target-binding competition cannot be ruled out with a likely negative impact on SPL7 function. A conceivable way to reinforce SPL7-mediated Cu deficiency responses could thus be the expression attenuation of other putative competing MRE-SPLs, e.g., through the expression of miR156/157.

In this study, we addressed two questions. First, is there any evidence for the role of the miR156-SPL module in the regulation of the $\mathrm{Cu}$ deficiency responses during plant development? Second, is the Cu-miRNA pathway globally or specifically influenced by developmental clues and by other abiotic stresses?

\section{Results}

\section{1. miR156 and Its Targets Expression under Different Copper Content}

In Arabidopsis, miR156 and miR157 isoforms are encoded by ten (miR156a-j) and four loci $(m i R 157 a-d)$, respectively (Supplementary Table S1). With the aim to test whether miR156 and miR157 expression is regulated by the presence of copper in the media, we analyzed by stem-loop RT-qPCR miR156 and miR157 mature levels. To this end, roots and shoots from 7-day-old wild-type (WT) seedlings were separately collected after growing in different copper concentrations. To that end, WT seeds were grown on MS medium $(0 \mathrm{Cu})$ and MS supplemented with $100 \mu \mathrm{M}$ BCS (100 BCS), $1 \mu \mathrm{M} \mathrm{Cu}(1 \mathrm{Cu})$ or $10 \mu \mathrm{M}$ $\mathrm{Cu}(10 \mathrm{Cu})$. These concentrations range from severe $\mathrm{Cu}$ deficiency $(100 \mathrm{BCS})$, deficiency $(0 \mathrm{Cu})$, sufficiency $(1 \mathrm{Cu})$ to slight $\mathrm{Cu}$ excess $(10 \mathrm{Cu})$. In order to confirm $\mathrm{Cu}$ deficiency, increase in the Cu-miRNA miR408 levels was monitored as control. As shown in Figure 1, miR408 expression increased both in roots and shoots as copper decreased in the media, with higher expression levels in roots under severe $\mathrm{Cu}$ deficiency. The analysis of the miR156 transcript levels shows that it is higher in shoots, where it is induced under both excess and severe deficiency of copper with respect to $\mathrm{Cu}$ sufficiency (Figure 1). The results 
for miR157 expression are similar to those obtained for miR156 with slightly increased expression, but not significant, under both very low and high copper levels compared to control conditions. The main difference with miR156 is that the expression levels in roots and shoots were similar for miR157 (Figure 1). Furthermore, it has been described that miR172 is downstream regulated by miR156 [10,22], so we also analyzed in the same conditions the miR172 expression. Accordingly, the pattern of miR172 expression was the opposite of the miR156 under severe $\mathrm{Cu}$ deficiency, showing slightly reduced expression (Figure 1).
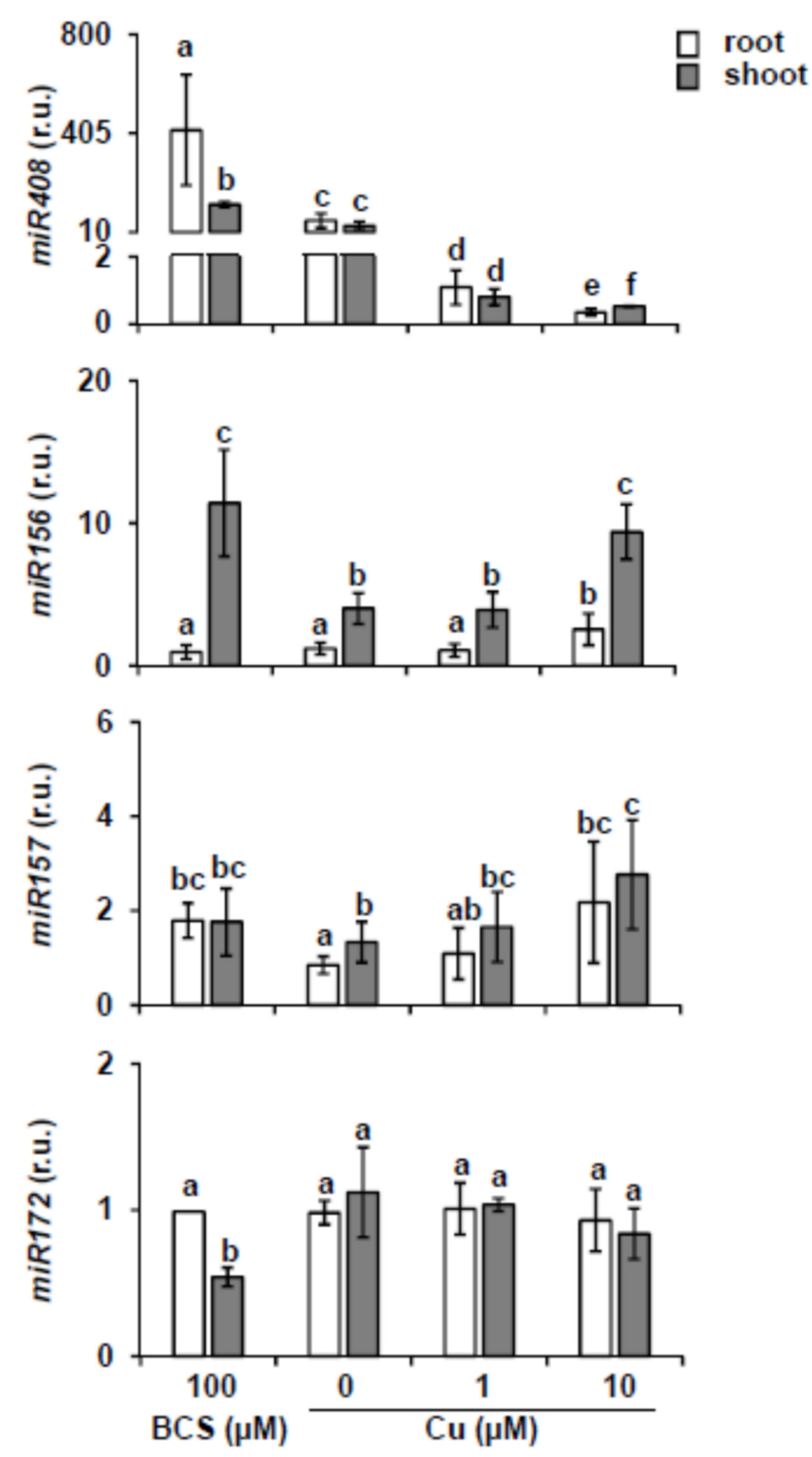

Figure 1. miR408, miR156, miR157 and miR172 expression levels at different copper concentrations. Relative expression of miR408, miR156, miR157 and miR172 genes in roots (white bars) and shoots (gray bars) from 7-day old WT seedlings grown under severe $\mathrm{Cu}$ deficiency (MS $0 \mu \mathrm{M} \mathrm{Cu}+100 \mu \mathrm{M}$ BCS), Cu deficiency (MS $0 \mu \mathrm{M} \mathrm{Cu}$ ), Cu sufficiency (MS $+1 \mu \mathrm{M} \mathrm{Cu}$, control) and $\mathrm{Cu}$ excess (MS $+10 \mu \mathrm{M} \mathrm{Cu}$ ). Samples were collected at zeitgeber time $12 \mathrm{~h}$. After miRNA extraction, specific primers were used for stem-loop RT-qPCR and expressed as relative units (r.u.). $18 \mathrm{~S}$ rRNA was used as internal control and the levels in the WT root sample grown under $\mathrm{Cu}$ sufficiency are arbitrarily set at one for comparison. The bars represent the mean \pm SD of three biological replicates. Means with a different letter are significantly different $(p<0.05)$. 
In order to know if there is a miR156 and miR157 transcriptional regulation depending on the copper nutritional status, we used transgenic plants where different miR156 ( $a, b$ and $d$ ) and miR157 $(a-c)$ promoters are fused to the reporter gene $\beta$-glucuronidase (GUS) (Figure S1) [13]. GUS activity directed by the miR156a, miR156d and miR156h promoters was detected in 7-day-old seedlings mainly in shoots under $\mathrm{Cu}$ deficiency (Figure S1). In the case of GUS activity for miR157a, miR157b and miR157c, it was detected in the cotyledon's vascular bundles under $\mathrm{Cu}$ deficiency. miR156 and miR157 GUS activity is also observed in sufficiency and excess of copper (results not shown). Furthermore, analysis of promoter regions up to $2 \mathrm{~kb}$ upstream of the miR156/157 pre-miRNA coding sequences indicates the presence of putative $\mathrm{Cu}$ deficiency cis-regulatory elements (GTAC boxes) in all of them (Supplementary Table S1).

The miR156 and miR157 regulate the expression of MRE-SPLs at a posttranscriptional level, among these is SPL3 $[13,14]$. Other SPLs, such as SPL7 and SPL8, are not targets of $m i R 156 / 157$. In order to check the expression of SPL members, targets and non-targets of miR156, in response to copper availability, 7-day-old WT seedlings were grown on MS medium $(0 \mu \mathrm{M} \mathrm{Cu})$ and MS supplemented with $100 \mu \mathrm{M}$ BCS $(100 \mathrm{BCS}), 1 \mu \mathrm{M} \mathrm{Cu}(1 \mathrm{Cu})$ or $10 \mu \mathrm{M} \mathrm{Cu}(10 \mathrm{Cu})$ and the transcript levels were analyzed by RT-qPCR (Figure 2). Upregulation under $\mathrm{Cu}$ deficiency of FSD1 expression, used as a control, confirmed proper $\mathrm{Cu}$ deficiency responsiveness of the analyzed samples (Figure 2). According to the increased miR156/157 expression under severe Cu deficiency, SPL3 was slightly down-regulated when BCS was added in the medium or when copper is in excess (Figure 2), whereas the relative expression of SPL7 and SPL8 genes was not significantly affected by copper treatment (Figure 2).

In order to know whether the SPL3 expression under $\mathrm{Cu}$ deficiency is dependent on SPL7 through the effect on miR156, we examined SPL3 expression in 7-day-old WT and spl7 mutant seedlings grown under $\mathrm{Cu}$ deficiency (MS) and Cu-excess (MS with $10 \mu \mathrm{M} \mathrm{Cu}$ ). Results show that an increased SPL3 expression is observed in spl7 mutant seedlings compared to the WT under Cu-excess. However, SPL3 expression under slight $\mathrm{Cu}$ deficiency was not significantly different (Figure 3A). Accordingly, SPL3 expression under Cu-sufficiency was similar in WT and spl7 seedlings, while it was significantly increased in the spl7 mutant under severe Cu deficiency (data not shown). Moreover, since it was mostly expressed in flowers, SPL3 transcript levels were also checked in this tissue (Figure S2A). Surprisingly, SPL3 expression in flowers was reduced in the spl7 mutant (Figure S2A). Nevertheless, since at least part of the miR156-dependent regulation is the result of translational inhibition (Gandikota et al., 2007), protein levels should be also checked. Instead, the expression of two of the SPL3 targets, APETALA 1 (AP1) and FRUITFULL (FUL), was analyzed and accordingly reduced in flowers (Figure $\mathrm{S} 2 \mathrm{~B}, \mathrm{C}$ ). These results pointed to a complex regulation of SPL3 depending on $\mathrm{Cu}$ status along development.

The presence of GTAC boxes in the SPL3 promoter (data not shown) and the putative connection between copper homeostasis and the circadian clock [62] prompted us to further pursue the regulation of SPL3 by copper in seedlings. To check SPL3 expression under light/dark conditions (12 h light and temperature cycles; L) and continuous darkness (etiolated seedlings with $12 \mathrm{~h}$ temperature cycles; D), WT seedlings were grown for $7 \mathrm{~d}$ in $\mathrm{Cu}$-deficient and Cu-excess media, samples were collected at zeitgeber time 0 and $12 \mathrm{~h}$ and gene expression was analyzed by RT-qPCR (Figure 3B). SPL3 transcription shows a differential expression pattern between 0 and $12 \mathrm{~h}$, being higher at 0 than at $12 \mathrm{~h}$. However, there is a slight SPL3 induction under slight Cu deficiency at $0 \mathrm{~h}$ in neutral photoperiod (12 h of Light and Dark, $23{ }^{\circ} \mathrm{C}$ Hot $16^{\circ} \mathrm{C}$ Cold; LDHC) (Figure 3B). In etiolated plants, SPL3 gene expression is attenuated regardless of the conditions (Figure 3B). These results point to a complex SPL3 expression pattern probably depending on the light, circadian rhythms and copper content, maybe acting throughout interconnected pathways. 

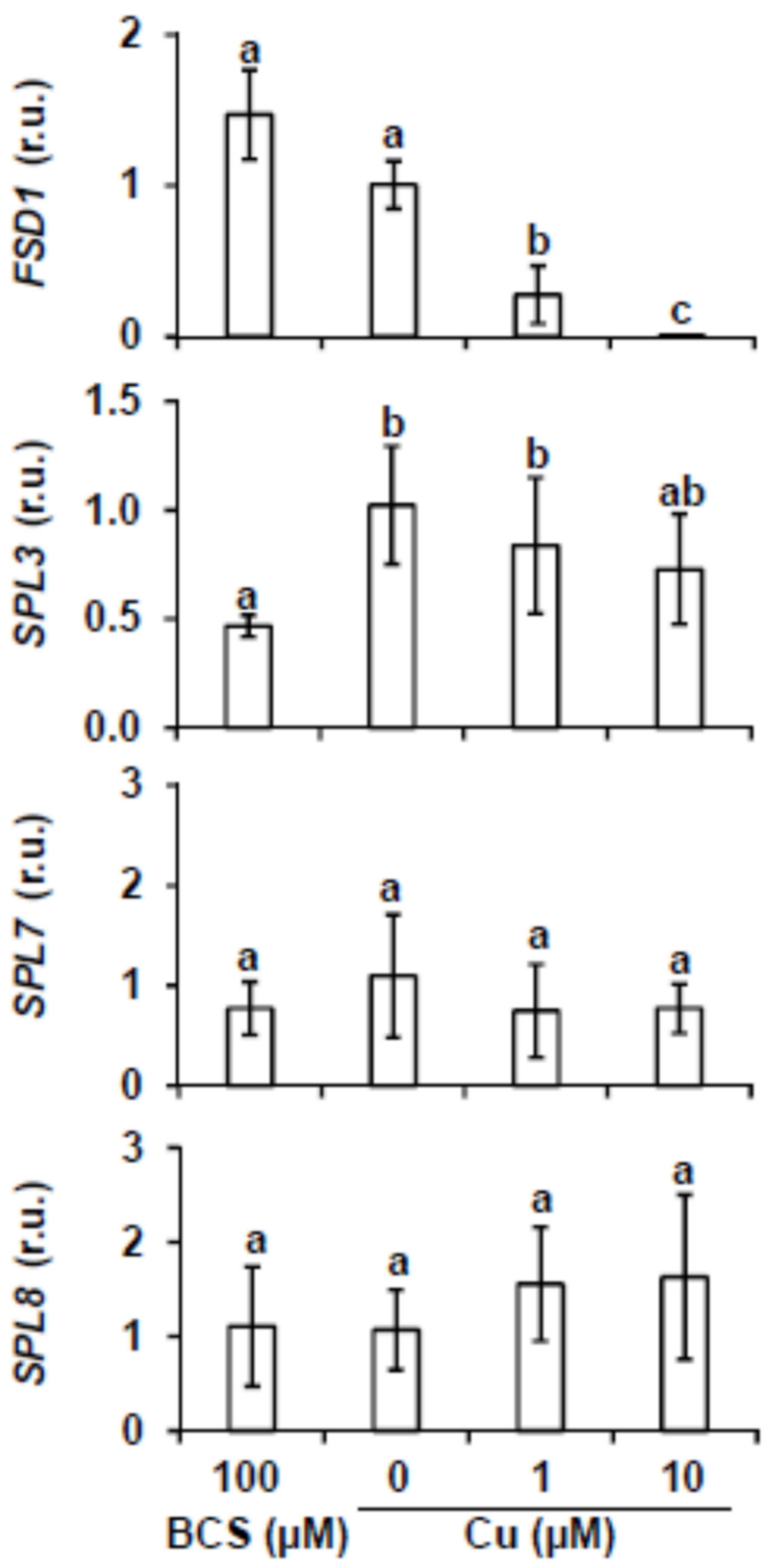

Figure 2. FSD1, SPL3, SPL7 and SPL8 expression at different copper concentrations. Relative expression of SPL3, SPL7 and SPL8 genes from 7-day old WT seedlings grown under severe $\mathrm{Cu}$ deficiency (MS $0 \mu \mathrm{M} \mathrm{Cu}+100 \mu \mathrm{M}$ BCS), Cu deficiency (MS $0 \mu \mathrm{M} \mathrm{Cu}), \mathrm{Cu}$ sufficiency (MS + $1 \mu \mathrm{M} \mathrm{Cu}$, control) and $\mathrm{Cu}$ excess (MS $+10 \mu \mathrm{M} \mathrm{Cu}$ ). After total RNA extraction, specific primers were used for RT-qPCR and expressed as relative units (r.u.). UBQ10 gene expression was used as internal control and levels in the WT sample grown under $\mathrm{Cu}$ sufficiency are arbitrarily set at one for comparison. The bars represent the mean \pm SD of three biological replicates. Means with a different letter are significantly different $(p<0.05)$. 
A

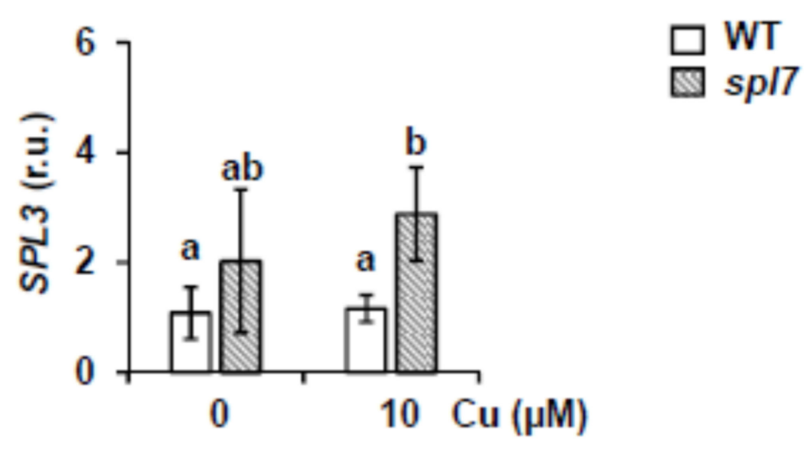

B

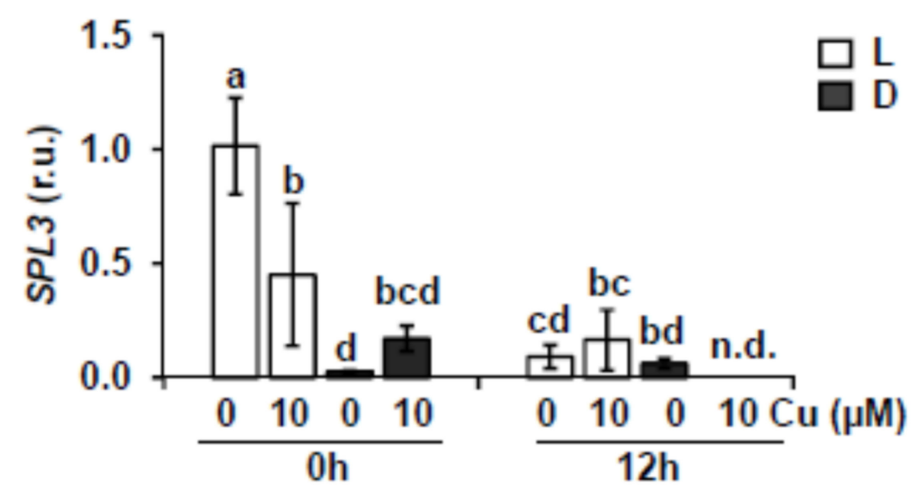

Figure 3. SPL3 expression under different metal conditions. (A) SPL3 relative expression in 7-day-old WT (white bars) and spl7 (striped bars) seedlings grown under). (B) SPL3 relative expression in 7-day-old WT seedlings grown under Cu deficiency (MS $0 \mu \mathrm{M} \mathrm{Cu}$ ) and Cu excess (MS with $10 \mu \mathrm{M}$ $\mathrm{Cu}$ ) and neutral photoperiod (12L/12D; white bars) or etiolated plants (24D; gray bars). Samples were collected at zeitgeber time 0 and $12 \mathrm{~h}$. After total RNA extraction, specific primers were used for RT-qPCR and expressed as relative units (r.u.). UBQ10 gene was used as internal control and the WT sample grown under $\mathrm{Cu}$ deficiency at zeitgeber time $0 \mathrm{~h}$ of light is arbitrarily set at one for comparison. The bars represent the mean \pm SD of three biological replicates. Means with a different letter are significantly different $(p<0.05)$. n.d.: not detected.

\subsection{Phenotype of SPL3 Overexpressing Plants under Different Copper Status}

To reduce the complexity of SPL3 regulation, we determined whether the growth of the miR156-resistant SPL3 overexpressing plants $\left(S P L 3^{O E}\right)[16,17]$ would be by copper shortage. For this, WT and $S P L 3^{O E}$ seedlings were grown for $7 \mathrm{~d}$ under deficiency, sufficiency and excess of copper. As shown in Figure 4, no obvious differences in growth were observed with respect to WT seedlings under $\mathrm{Cu}$ deficiency and sufficiency. However, under severe $\mathrm{Cu}$ deficiency, the root length is significantly more affected in SPL3 ${ }^{O E}$ seedlings (Figure 4). A slightly relative decrease in root length was also observed under $\mathrm{Cu}$-excess in these seedlings (Figure 4). Aiming to exacerbate deficiency conditions, WT and SPL3 ${ }^{O E}$ seedlings were grown for $18 \mathrm{~d}$ under severe Cu deficiency (MS with $100 \mu \mathrm{M}$ BCS) and their growth was compared to each other and to growth under $\mathrm{Cu}$-sufficiency (MS with $1 \mu \mathrm{M}$ ) conditions (Figure S3A). Total root length, number of lateral roots and the growth rate, measured as the ratio of total length/number of roots, serve to quantify the observed phenotype. For all these parameters, $S P L 3^{O E}$ seedlings show lower values than WT (Figure S3B), indicating that they are more sensitive to severe $\mathrm{Cu}$ deficiency. 
A

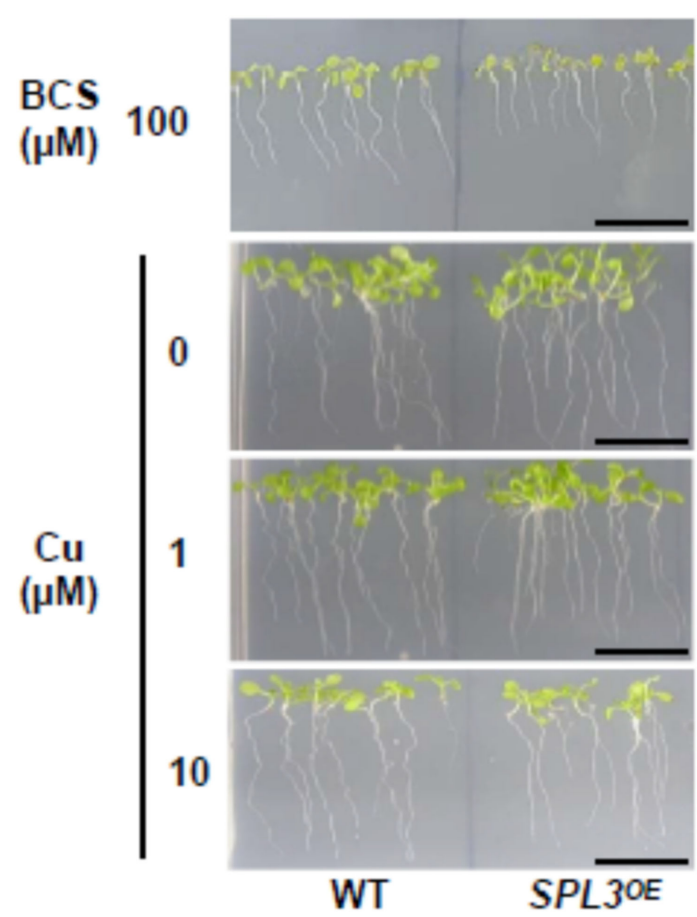

B

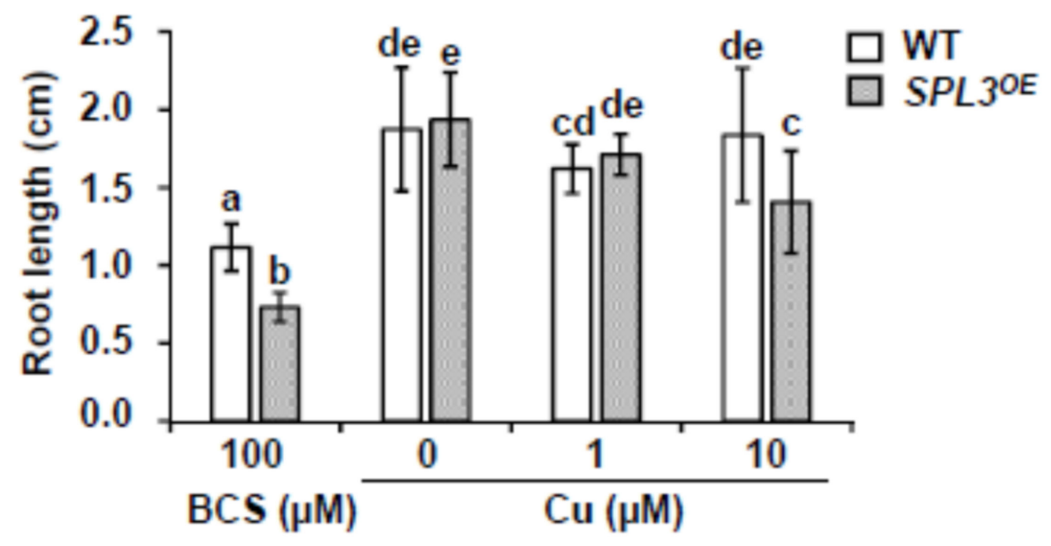

Figure 4. Phenotype of the $S P L 3^{O E}$ seedlings at different copper concentrations. (A) Photographs of 7-day-old WT and SPL3 ${ }^{O E}$ seedlings grown under severe Cu deficiency (MS $0 \mu \mathrm{M} \mathrm{Cu}+100 \mu \mathrm{M} B C S$ ), $\mathrm{Cu}$ deficiency (MS $0 \mu \mathrm{M} \mathrm{Cu}$ ), Cu sufficiency (MS $+1 \mu \mathrm{M} \mathrm{Cu}$, control) and Cu excess (MS $+10 \mu \mathrm{M}$ $\mathrm{Cu}$ ). (B) Root length of WT (white bars) and $S P L 3^{O E}$ (dotted bars) seedlings in the same conditions that are indicated in (A). The bars represent the mean $\pm \mathrm{SD}$ of ten biological replicates. Means with a different letter are significantly different $(p<0.05)$. Scale bar $=1 \mathrm{~cm}$.

ICP-MS analysis revealed that copper content increased in both genotypes, in accordance with increasing copper concentrations in the medium (Figure 5). SPL3 ${ }^{O E}$ seedlings showed a lower copper content compared to the WT under $\mathrm{Cu}$ deficiency and sufficiency (Figure 5). This finding is in agreement with the observed higher sensitivity of SPL3 ${ }^{\mathrm{OE}}$ seedlings to $\mathrm{Cu}$ deficiency. 


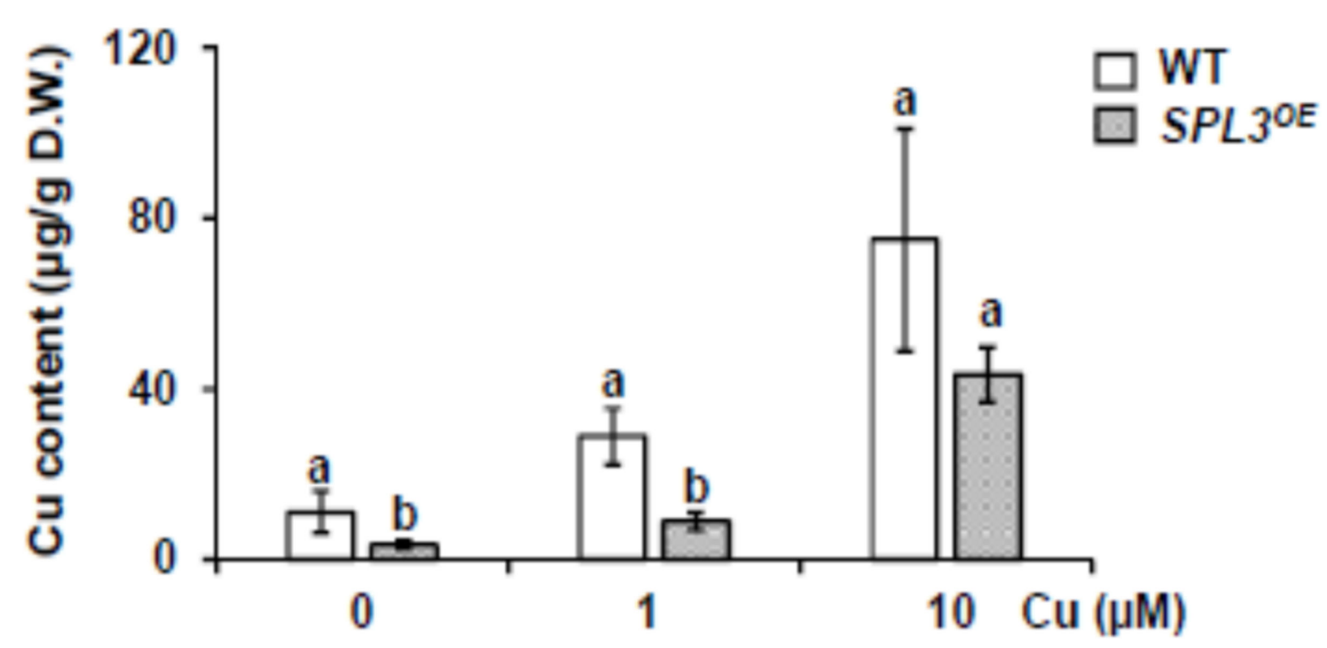

Figure 5. Copper content in SPL3 overexpressing plants. Total Cu content in 7-day-old WT (white bars) and $S P L 3^{O E}$ (dotted bars) seedlings grown under $\mathrm{Cu}$ deficiency (MS $0 \mu \mathrm{M} \mathrm{Cu}$ ), Cu sufficiency (MS $+1 \mu \mathrm{M} \mathrm{Cu}$, control) and $\mathrm{Cu}$ excess (MS $+10 \mu \mathrm{M} \mathrm{Cu}$ ). The bars represent the mean $\pm \mathrm{SD}$ of three biological replicates. Means with a different letter are significantly different with respect to their WT $(p<0.05)$.

\subsection{SPL7-Dependent Expression in SPL3 Overexpressing Plants}

To further understand the increased sensitivity to Cu deficiency shown by SPL3 ${ }^{O E}$ seedlings, we first analyzed by RT-qPCR the expression of FSD1, COPPER TRANSPORTER 2 (COPT2) and COPPER CHAPERONE (CCH), all genes typically related to $\mathrm{Cu}$ deficiency responses. Thereto, 7-day-old WT and $S P L 3^{O E}$ seedlings were grown under $\mathrm{Cu}$ sufficiency (MS supplemented with $1 \mu \mathrm{M}$ ) and Cu deficiency (MS) medium. As a control to assess SPL3 overexpression in our samples, the SPL3 expression was confirmed by RT-qPCR (Figure 6). WT seedlings grown under $\mathrm{Cu}$ deficiency showed an increased expression of COPT2, FSD1 and $\mathrm{CCH}$ with regard to the sufficiency condition (Figure 6). However, in $S P L 3^{O E}$ seedlings this induction was about 10 times lower for FSD1 and 12 times for COPT2, with respect to the induction observed in the WT. Furthermore, significant $\mathrm{CCH}$ induction under $\mathrm{Cu}$ deficiency conditions is not detected in the $S P L 3^{O E}$ seedlings (Figure 6). To determine whether the attenuation of the $\mathrm{Cu}$ deficiency response in $S P L 3^{O E}$ seedlings is mediated by $S P L 7$, we also analyzed its expression, but found no significant differences with respect to WT seedlings, or in dependence of copper concentration in the medium (Figure 6). These results indicate that the strongly attenuated response to Cu deficiency in SPL3 ${ }^{O E}$ plants is not mediated by changes in the expression of SPL7 at the transcriptional level. Furthermore, a reduced induction of the $\mathrm{Cu}$ deficiency response could also be observed in $S P L 3^{O E}$ flowers, where the expression of the main SPL7-dependent targets, such as COPT2 and FSD1, were again significantly reduced (Figure S5). In addition, miR156 and miR172 expression levels were determined in $S P L 3^{O E}$ seedlings at different copper concentrations and they remained mostly unaffected by this (Figure S4). 

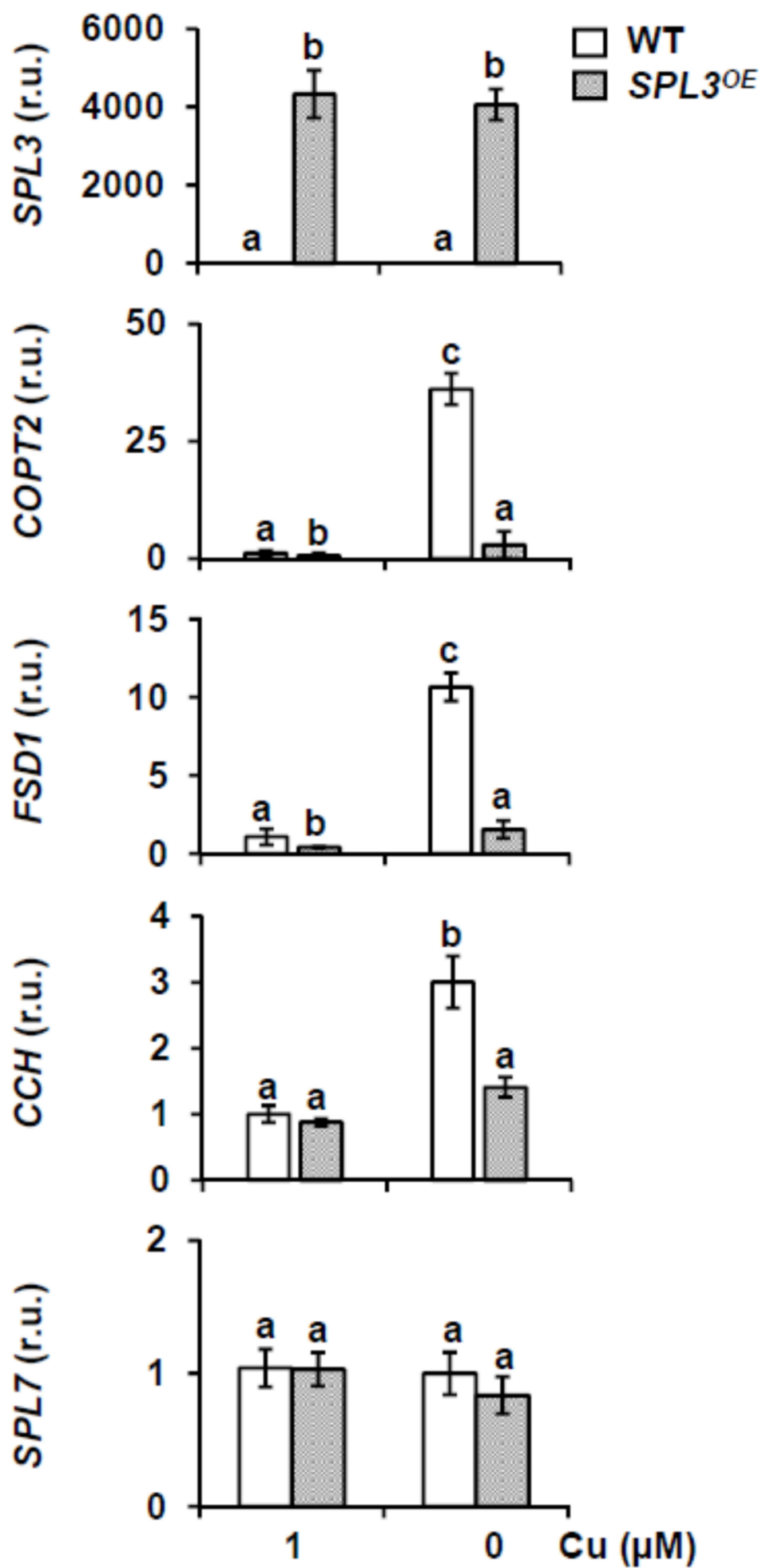

Figure 6. Expression of $\mathrm{Cu}$ deficiency markers in $S P L 3^{O E}$ seedlings. SPL3, FSD1, COPT2, CCH and $S P L 7$ relative expressions in 7-day-old WT (white bars) and SPL3 ${ }^{O E}$ (dotted bars) seedlings grown under $\mathrm{Cu}$ sufficiency (MS $+1 \mu \mathrm{M} \mathrm{Cu}$, control) and Cu deficiency (MS $0 \mu \mathrm{M} \mathrm{Cu}$ ). After total RNA extraction, specific primers were used for RT-qPCR and expressed as relative units (r.u.). UBQ10 gene was used as internal control and the WT sample grown under $\mathrm{Cu}$ sufficiency is arbitrarily set at one for comparison. The bars represent the mean \pm SD of three biological replicates. Means with a different letter are significantly different $(p<0.05)$. 
To assess whether the attenuation of the Cu deficiency response observed in SPL3 ${ }^{O E}$ seedlings is a general effect caused by a competition for GTAC binding sites in promoters of target genes that might be caused by overexpression of any other SPL factor, we analyzed the relative expression of the $\mathrm{Cu}$ deficiency markers FSD1, COPT2 and $C C H$ in SPL $8^{O E}$ seedlings. SPL8 belongs to a distinct subfamily and differs among others from SPL3 by lacking a miR156 responsive element [13]. As shown in Figure S6, no major changes in the relative expression of $F S D 1, C C H$ and COPT2 genes were observed in SPL8 ${ }^{O E}$ seedlings with respect to $\mathrm{WT}$ when grown on $\mathrm{Cu}$-deficient medium. These results indicate that the effects of SPL3 overexpression on the attenuation of the $\mathrm{Cu}$ deficiency response are specifically mediated by SPL3 and they do not occur by overexpressing other SPL family members that are not miR156 targets, such as SPL8. Although this suggests that the effects might be mediated by the miR156-SPL module, its universal truth remains to be investigated with other MRE-SPL members.

\subsection{Cu-miRNA and Target Expression in SPL3 Overexpressing Plants}

In order to study the effects of SPL3 overexpression on $\mathrm{Cu}$-miRNA levels under $\mathrm{Cu}$ deficiency, the expression of two well-conserved Cu-miRNAs, miR408 and miR398, was analyzed. As shown in Figure 7, miR408 expression was higher under $\mathrm{Cu}$ deficiency, but in comparison to WT, slightly reduced in $S P L 3^{O E}$ seedlings in both roots and shoots. This could be expected from a SPL7-mediated response and is in accordance with the previously observed attenuation of the $\mathrm{Cu}$ deficiency response in $S P L 3^{O E}$ transgenics (Figure 6). Although showing a similar response to that of miR408, the expression of miR398 in the roots of the $S P L 3^{O E}$ seedlings under $\mathrm{Cu}$ deficiency, however, was not attenuated as expected (Figure 7).
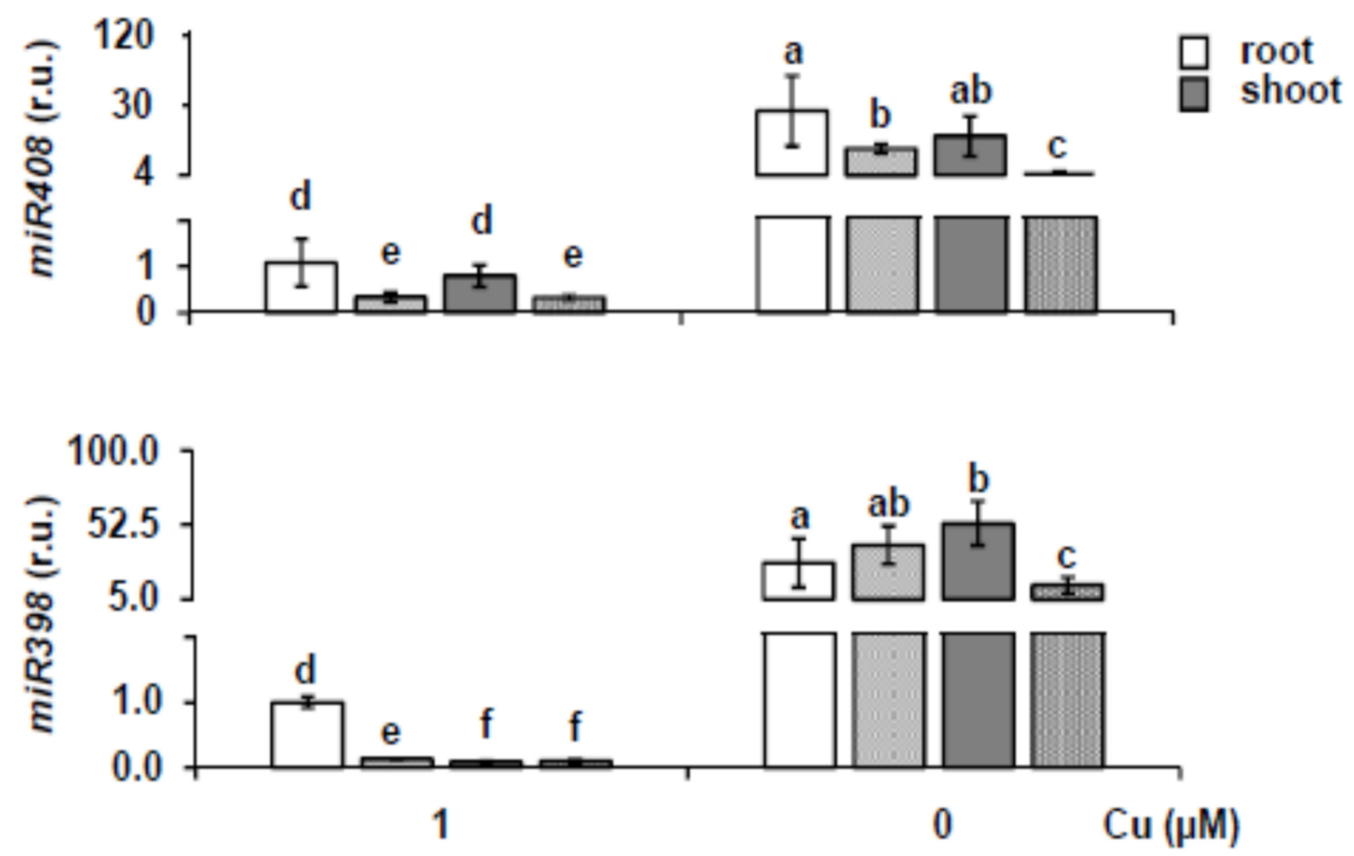

Figure 7. Expression of mature $m i R 398$ and $m i R 408$. Relative expression of $m i R 398$ and $m i R 408$ genes in roots (white bars) and shoots (gray bars) from 7-day-old WT (smooth background) and $S P L 3^{O E}$ (dotted background) seedlings grown under $\mathrm{Cu}$ deficiency (MS $0 \mu \mathrm{M} \mathrm{Cu}$ ) and $\mathrm{Cu}$ sufficiency (MS + $1 \mu \mathrm{M} \mathrm{Cu}$, control). After miRNA extraction, specific primers were used for stem-loop RTqPCR and expressed as r.u. (relative units). $18 S$ gene was used as internal control and the WT root sample grown under $\mathrm{Cu}$ sufficiency is arbitrarily set at one for comparison. The bars represent the mean \pm SD of three biological replicates. Means with a different letter are significantly different $(p<0.05)$. 
To know if their respective targets respond as expected to the changes in miR408 and miR398 levels as observed in the comparison between $S P L 3^{O E}$ transgenics and WT, their expression was analyzed (Figure 8). In accordance with the relative reduced miR408 expression, under $\mathrm{Cu}$ deficiency, the transcript levels of its target ARPN (encoding PLANTACYANIN) were found to be higher in SPL3 ${ }^{O E}$ compared to WT seedlings (Figure 8). However, in the case of miR398-targeted CSD1 transcripts (encoding $\mathrm{Cu} / \mathrm{ZnSOD}$ ), the levels remained lower in $S P L 3^{O E}$ seedlings compared to WT under any conditions (Figure 8). These results indicate that the partial down-regulation of miR398 under $\mathrm{Cu}$ deficiency in $S P L 3^{O E}$ seedlings does not translate into the induction of its target (Figure 8), possibly reflecting the interferences of other processes such as oxidative stress, in the regulation of CSD2.
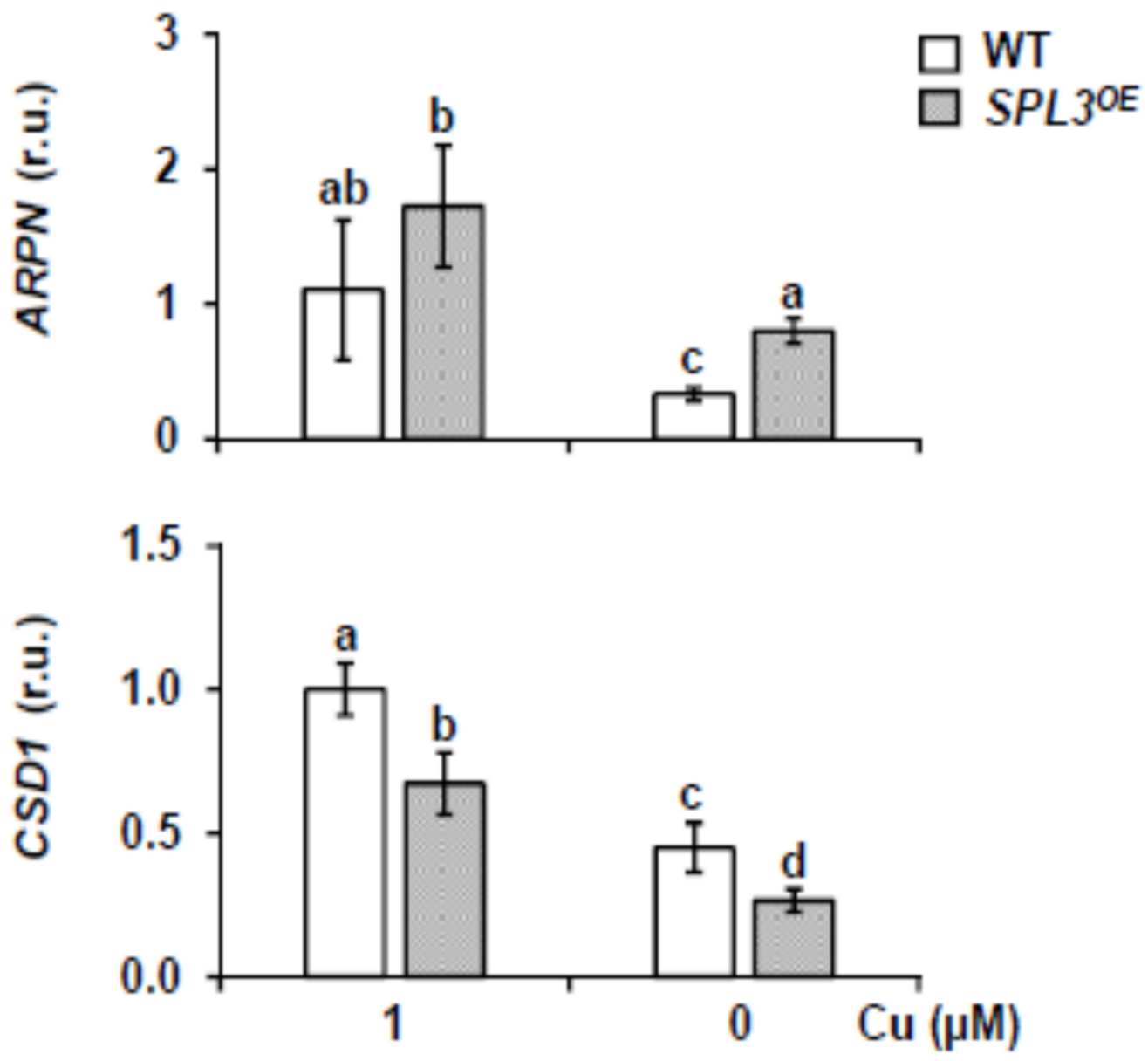

Figure 8. Expression of the miR398 and miR408 targets in SPL3 ${ }^{O E}$ seedlings. Relative expression of CSD1 and ARPN in 7-day-old WT (white bars) and SPL3 ${ }^{O E}$ (dotted bars) seedlings grown in the same conditions as in Figure 5. After total RNA extraction, specific primers were used for RT-qPCR and expressed as relative units (r.u.). UBQ10 gene was used as internal control and the WT sample grown under $\mathrm{Cu}$ sufficiency is arbitrarily set at one for comparison. The bars represent the mean \pm SD of three biological replicates. Means with a different letter are significantly different $(p<0.05)$. 


\section{Discussion}

\subsection{The miR156-SPL Module Affects SPL7-Mediated Cu deficiency Responses}

Despite the generally observed rapid evolution of miRNAs, miR156 is highly conserved in plants as well as its function in regulating the timing of developmental transitions [63]. Moreover, $\mathrm{Cu}-\mathrm{miRNAs}$, and miR398 and miR408 in particular, are also well conserved in plants [58-60]. Cu-miRNA up-regulation under $\mathrm{Cu}$ deficiency is mediated by SPL7 in a relatively well-known process (SPL7/Cu-miRNA pathway), although other abiotic but also biotic stresses may up- or down-regulate $\mathrm{Cu}$-miRNA expression $[8,9,46,48,56]$. Most small and medium size SPLs (MRE-SPLs), such as SPL3, are repressed by miR156/157 at the post-transcriptional level, either through transcript cleavage or translation block. However, this last possibility has not been studied yet in detail for most MRE-SPLs [15-17]. Their larger family members (non-MRE-SPLs), like SPL7, escape from a direct miR156/157 regulation. Whereas SPL7 is considered the main regulator of the $\mathrm{Cu}$ deficiency response in Arabidopsis [9,24], to our knowledge, a role in that response for other MRE-SPL family members has not been described yet. It is therefore interesting to investigate the possibility that the miR156-SPL module could affect SPL7-mediated Cu deficiency responses.

Here, we demonstrated that miR156/157 and their target MRE-SPL expression is under partial control of SPL7 in Arabidopsis seedlings subjected to Cu deficiency. This is based on the following observations. First, miR156/157 expression is found to be up-regulated under severe $\mathrm{Cu}$ deficiency and, consequently, the expression of its target SPL3 reduced (Figures 1 and 2). Second, SPL3 expression is found to be dependent on SPL7 under Cuexcess (Figure 3A) and flowering (Figure S2). Both observations may well be explained by the direct regulation of miR156 levels by SPL7. In agreement with this is the presence of a high number of CuRE motifs in several of the miR156/157 promoters (Table S1—see for example the $8 \mathrm{GTAC}$ in the miR156d promoter. Most importantly, miR156c up-regulation by $\mathrm{Cu}$ deficiency in WT shoots is almost abolished in the spl7 mutant, as has been shown by Bernal et al. [9] in an RNA-seq experiment $(\mathrm{WT}+\mathrm{Cu}=0.2 ; \mathrm{WT}-\mathrm{Cu}=0.7 ; s p l 7+\mathrm{Cu}=0.2$; spl7 $-\mathrm{Cu}=0.3)$. In the same experiment, and in full accordance, the miR156 validated MRESPL targets, such SPL2, SPL3 and SPL4, were found to be down-regulated in WT under $\mathrm{Cu}$ deficiency but not in the spl7 mutant (see for example the RNA-seq values in the case of the SPL2 target: $\mathrm{WT}+\mathrm{Cu}=32.1 ; \mathrm{WT}-\mathrm{Cu}=15.7 ; \mathrm{spl7}+\mathrm{Cu}=20.9 ; \mathrm{spl7}-\mathrm{Cu}=20.3)$ [9]. Taken together, these results indicate that under Cu deficiency increased miR156 expression, possibly miR156c in particular, and subsequent repression of SPL3 (Figures 1 and 2) could be mediated by SPL7 resulting in a feedback tuning of Cu deficiency responses on the miR156-SPL module (Figure 9). 


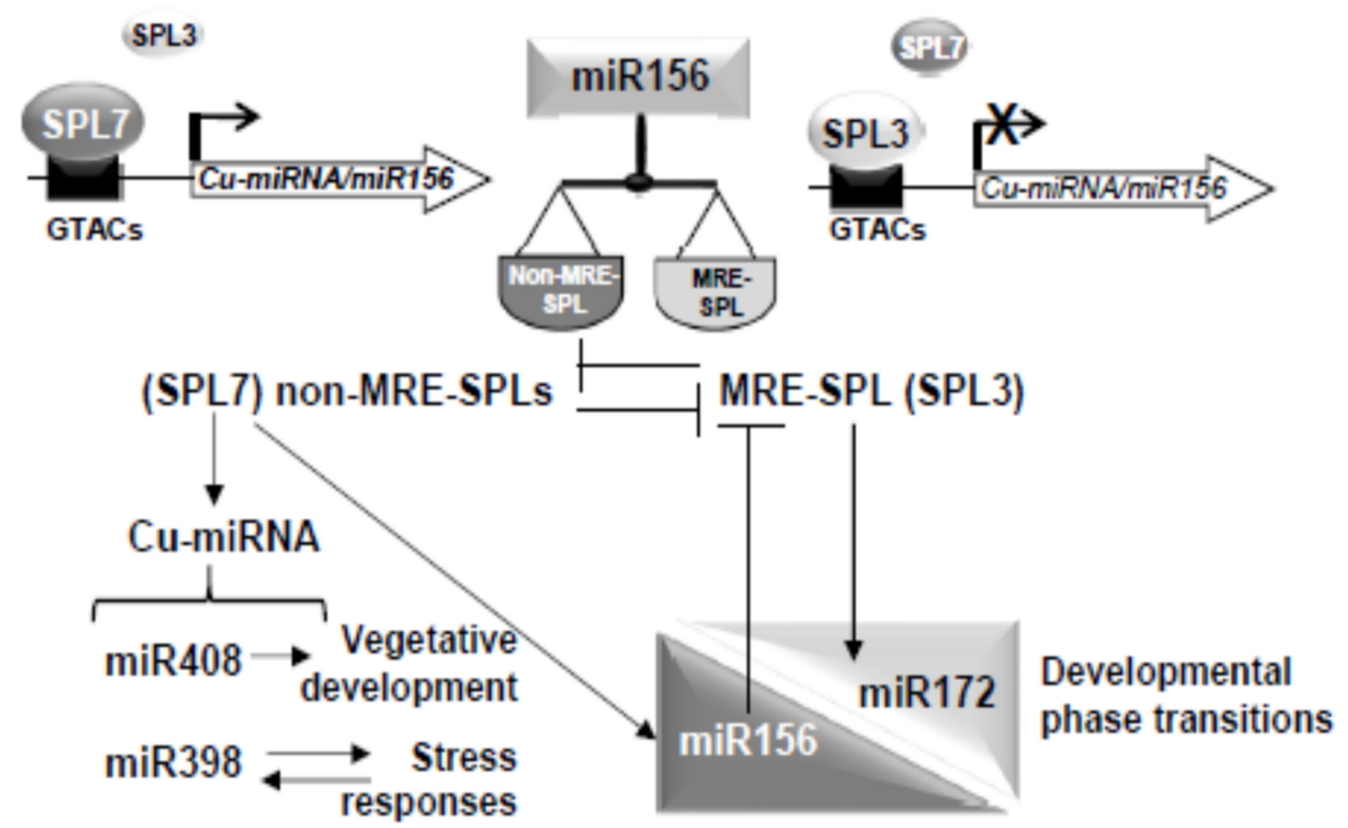

Figure 9. Model of the interplay between the SPL7/Cu-miRNA pathway and the miR156-SPL module. SPL7 mediated the transcriptional regulation of $C u$-miRNA, such as miR408 and miR398, and possibly the miR156. miR156 expression by targeting MRE-SPL, such as SPL3, controls their transcriptional function. MRE-SPL might compete with non-MRE-SPL, such as SPL7, to bind cis-elements (GTACs) in the SPL target promoters precluding transcriptional productive binding. Thus, miR156 could ultimately control the MRE-SPL/non-MRE-SPL ratio and, subsequently, their functionality. This control is exemplified by the balance between SPL3 and SPL7, as demonstrated by a Cu deficiency attenuated transcriptional response in the SPL3 ${ }^{O E}$ plants. The effects on $\mathrm{Cu}$-miRNA include both common (miR408) and specific (miR398) responses depending on other environmental conditions and the degree to which the plant life cycle has progressed.

\subsection{SPL3 Overexpression Inhibits the SPL7 Transcriptional Activation}

The other way around, the miR156-SPL module seems also to affect $\mathrm{Cu}$ deficiency responses, possibly as an integral part of developmental regulation (Figure 9). This finds support in the increased sensitivity of $S P L 3^{O E}$ seedlings growing under $\mathrm{Cu}$ deficiency (Figures 4 and S3) and the greatly attenuated induction of Cu deficiency markers, such as FSD1, COPT2 and CCH (Figure 6) [8,9,64]. Competition between SPL7 and SPL3 TFs for GTAC binding motifs in the promoters of target genes, such as FSD1, COPT2, CCH and $\mathrm{Cu}$-miRNAs, could provide a mechanistic explanation (Figure 9). Although this hypothesis requires further experimental confirmation, competitive binding to GTAC motifs has been proposed for small SPL members in the case of reproductive development, causing substantial functional redundancy [27]. Functional redundancy between SPL1 and SPL12 has been also reported $[34,35]$. Importantly, whereas SPL7 binding results in transcriptional activation of target $\mathrm{Cu}$ deficiency genes, the occupancy of binding sites by SPL3 seems to inhibit their transcriptional activation, possibly due to differences in the interaction with other factors. In this sense, non-productive binding by other MRE-SPLs to the GTAC motifs would redound in inhibition of the SPL7-mediated response (Figure 9). Accordingly, the $S P L 3^{O E}$ phenotype resembled that of the spl7 mutant with respect to the sensitivity to $\mathrm{Cu}$ deficiency and a lower $\mathrm{Cu}$ content due to the lack of COPT2 induction [9,65]. However, relevant competition seems to be restricted to SPL3 and maybe other MRE-SPLs, since overexpression of the non-MRE-SPL, SPL8, has no significant effect. A plausible explanation could be that SPL8 does not contain the "extended SBP" domain, with a highly conserved sequence whose function still remains unknown [66]. 
Considering the well-known role of copper in plant fertility by improving grain/seed yield [1] and the established function of the miR156-SPL module in the control of developmental phase transitions in plants [10], next we wonder about the interplay of the miR156-SPL module with the SPL7-mediated Cu deficiency responses during life cycle progression. Our results suggest that both responses, the SPL7 effect on the expression of the miR156-SPL module (Figures 3A and S2) and the miR156-SPL module influence on $\mathrm{Cu}$ deficiency (Figures 6 and S5), change as the life cycle progresses. Possibly, these effects allow a stronger $\mathrm{Cu}$ deficiency response in seedlings compared to adult plants, since induction of $\mathrm{Cu}$ deficiency markers in flowers was not as strong as in seedlings (Figures 6 and S5). The main phenotype of $S P L 3^{O E}$ plants is early flowering, in accordance with SPL3 promoting the transition from vegetative to reproductive phase [67]. As copper demand is higher during reproductive development [1], SPL3 abundance may eventually interfere under $\mathrm{Cu}$ deficiency at that developmental stage. SPL3 is subjected to a complex spatiotemporal regulatory network (Figure 3B). The interaction described between SPL7 and ELONGATED HYPOCOTYL5 (HY5) further underscores a connection between copper homeostasis and light [57]. Moreover, it has been described that miR172 induces a set of SPLs, among which is SPL3, through their targets [68]. This means that miR156 and miR172 exert opposite effects on SPL3 expression [22]. Although $S P L 3^{O E}$ plants have been used here in order to circumvent the complex SPL3 expression pattern, further research will be needed in order to sustain a physiological role of SPL3 in Cu deficiency responses at the plant reproductive phase. At the molecular level, it would be interesting to know how the SPL7 TF could be differentially functioning along the plant life cycle progression. The $\mathrm{Cu}$ deficiency-induced transcription factor (CIFT1) plays roles in Cu uptake into roots and copper delivery to flowers, although the interaction between SPL7 and CIFT1 in mediating $\mathrm{Cu}$ deficiency responses has not been completely dissected yet [69].

\subsection{SPL7/Cu-miRNA Pathway Is Influenced by Developmental and Stress Processes}

Putting the focus back on the SPL7/Cu-miRNA pathway, we wonder if it is globally or specifically influenced by developmental cues and by other abiotic stresses. SPL7 has been recently described to function during the adaptation to salt stress [70]. Under our experimental conditions, the expression of the miR408 and its target, ARPN, is attenuated in $S P L 3^{O E}$ plants (Figures 7 and 8 ) in agreement with other Cu deficiency markers (Figure 6). We have recently proposed that $\mathrm{Cu}$-miRNAs could act as post-transcriptional Modulators of Metalloprotein messenger RNA (ModMeR) [71]. Thus, Cu-miRNAs could participate in intracellular metal distribution by establishing a metalation ranking which prioritize essential versus non-essential metalloproteins [72]. Constitutive expression of miR408 results in enhanced growth while decreased miR408 expression caused impaired growth [55-57]. Thus, by decreasing copper delivery to extracellular multicopper oxidases, increased miR408 levels will benefit copper delivery to essential cuproproteins, such as plastocyanin, improving plant biomass and seed yield. In this sense, miR408 has been proposed to be a modulator of vegetative growth in response to environmental cues [55-57]. However, altered levels of miR408 have detrimental effects on the response to other stresses, such as iron deficiency [54].

On the other hand, and contrary to miR408, the miR398 and in particular its target, CSD1, showed a differential response in SPL3 ${ }^{O E}$ plants (Figures 7 and 8) compared to other $\mathrm{Cu}$ deficiency markers (Figure 6). A possible explanation could be that miR398 and /or its targets could also respond to other stress signals. Due to the role of SODs in the antioxidant responses, most probably oxidative stress signaling is part of the miR398 expression response in $S P L 3^{O E}$ plants. In fact, miR398 has been reported to be up-regulated under multiple conditions where oxidative stress increased and, accordingly, putative stressresponsive cis-elements were found in miR398 promoters [46]. Furthermore, CSD2 mRNA levels were not negatively correlated with miR398 levels under certain stress conditions, suggesting the existence of miR398-dependent and independent regulatory mechanisms for CSD2 expression [46]. These results point to diverse influences on the different $\mathrm{Cu}$-miRNAs, 
possibly depending on additional signaling pathways and the responsiveness of $\mathrm{Cu}$-miRNA promoters to these signals.

Taken together, our results suggest an interaction between the miR156-SPL module and the SPL7-mediated $\mathrm{Cu}$ deficiency responses. Another putative MRE-SPL and nonMRE-SPL interaction has been also described. It has been demonstrated that miR156, acting through MRE-SPLS, such as SPL2 and SPL11, is a factor involved in the tolerance to recurring environmental stress [73], whereas the non-MRE-SPLS, SPL1 and SPL12, have been implicated in conferring thermotolerance in the reproductive stages [35]. The miR156 levels do not only change under severe $\mathrm{Cu}$ deficiency and heat stress, but also in response to various other stresses such as cold, salt, and drought stress, as well as UV-B radiation, hypoxia, and biotic stress [73-75]. It has been hypothesized that miR156 acts as a licensing factor for the transition to flowering [22]. Based on ours and others' results, a general picture is emerging, where the miR156 control of the MRE-SPL/non-MRE-SPL ratio and, subsequently, their functions could be a key factor in the interplay between developmental and stress responses. Thus, stress-mediated induction of miR156 may delay the transition to flowering by prolonging the juvenile phase and serve to avoid flowering during the stress conditions. In this way, $\mathrm{Cu}$ deficiency responses would be stronger in young than in adult plants, and prolonging the juvenile phase would thus help plants to overcome a period of unfavorable conditions to increase the chance of successful reproduction later. It is conceivable that the SPL7/Cu-miRNA pathway, by promoting vegetative growth and increased tolerance to environment abiotic stress, would be integrated with the miR156-SPL module in regulating these responses along the plant life cycle (Figure 9). These results reflect in part the delicate compromises that plants, being sessile organisms, need to make during different stages of their life cycle when facing nutritional deficiency and other stress conditions.

\section{Materials and Methods}

\subsection{Plant Growth Conditions and Treatments}

Seeds of $A$. thaliana ecotype Columbia-0 (Col-0), the SPL $3^{O E}$ and $S P L 8^{O E}$ transgenic lines and the spl7 mutant were surface-sterilized, stratified for 2 days at $4{ }^{\circ} \mathrm{C}$ and germinated in MS medium plates. The solution was prepared by adding macronutrients (Sigma, St. Louis, MO, USA) and micronutrients consisting of a mix of $50 \mathrm{mM} \mathrm{H}_{3} \mathrm{BO}_{3}, 36.6 \mathrm{mM} \mathrm{MnSO}_{4}$ $\mathrm{H}_{2} \mathrm{O}, 15 \mathrm{mM} \mathrm{ZnSO}_{4} 7 \mathrm{H}_{2} \mathrm{O}, 0.57 \mathrm{mM} \mathrm{Na}_{2} \mathrm{MoO}_{4} 2 \mathrm{H}_{2} \mathrm{O}, 0.25 \mathrm{mM} \mathrm{KI}$, and $0.05 \mathrm{mM} \mathrm{CoCl}$ $6 \mathrm{H}_{2} \mathrm{O}$. Finally, $0.05 \%$ MES, $1 \%$ sucrose, and $0.8 \%$ phytoagar was added, and the $\mathrm{pH}$ was adjusted to 5.7-5.8 with diluted $\mathrm{KOH}$. Seedlings were grown as previously described [62] for 7 or 15 days with a $12 \mathrm{~h}$ neutral photoperiod $\left(65 \mathrm{mmol} \mathrm{m}^{-2}\right.$ of cool-white fluorescent light) at $23{ }^{\circ} \mathrm{C} / 16{ }^{\circ} \mathrm{C}$ temperature cycle. In order to obtain the indicated concentrations of $\mathrm{Cu}$, the medium was supplemented with 1 or $10 \mu \mathrm{M} \mathrm{CuSO}_{4}$. For severe copper deficiency $100 \mu \mathrm{M}$ BCS (Bathocuproinedisulfonic acid disodium salt) was added. Plants were grown in soil and irrigated with Hoagland's 0.5X solution as described previously [76]. Hydroponic cultures were performed from 3-4 true leaves' seedlings grown in commercial soil, which were transferred to black boxes containing standard Hoagland solution $(0.1 \mathrm{X}), \mathrm{pH} 5.8$, as described by [77]. After a 14-day adaptation, the $\mathrm{Cu}$ deficiency treatment (corresponding to a Hoagland medium without $\mathrm{Cu}$ sources) commenced. Media were changed weekly for $4-5$ weeks. Root length was measured using the ImageJ 1.42q software (NIH Bethesda, USA) (http://rsb.info.nih.gov./ij).

\subsection{Metal Accumulation Determinations}

$\mathrm{Cu}$ content was determined by ICP-MS as described previously $[76,78]$ at the Servei Central de Suport a la Investigació Experimental (SCSIE) of the Universitat de València. Briefly, lyophilized samples were digested with $\mathrm{HNO}_{3}$ at $100{ }^{\circ} \mathrm{C}$ and diluted with milli, $i_{Q}$ LUS water (Millipore-Merck Darmstadt, Germany). 


\subsection{GUS-Staining}

Assays were performed as described [79]. Briefly, the seedlings from the 7-day-old pMIR156:GUS and $p M I R 157: G U S$ transgenic lines [13] were embedded with the substrate solution (100 $\mathrm{mM} \mathrm{NaPO}_{4}, \mathrm{pH} 7.2,0.5 \mathrm{mM} \mathrm{K}_{3} \mathrm{Fe}(\mathrm{CN})_{6}, 0.5 \mathrm{mM} \mathrm{K}_{4} \mathrm{Fe}(\mathrm{CN})_{6}, 0.1 \%(v / v)$ Triton $\mathrm{X}-100,0.5 \mathrm{mM} 5$-bromo-4-chloro-3-indolyl- $\beta$-D-glucuronide (AppliChem), and $10 \mathrm{mM}$ EDTA, pH 7.2). Reactions took place at $37^{\circ} \mathrm{C}$ and were stopped with ethanol (70\%).

\subsection{Gene Expression by Real-Time Quantitative PCR and Stem-Loop Quantitative PCR}

Total Arabidopsis RNA and miRNA were isolated using the RNeasy Plant Mini Kit (Qiagen, Hilden, Germany) and MIRVANA (Ambion, Austin, TX, USA), respectively, was quantified by UV spectrophotometry and its integrity was visually assessed on ethidium bromide-stained agarose gels. After treatment with DNase I Amp Grade (Invitrogen, Waltham, MA, USA), cDNA was generated by retro-transcriptase SSII (Invitrogen, Waltham, MA, USA) as previously described [76,80]. Real-time quantitative PCR (RT-qPCR) or stem-loop RT-qPCR was carried out with SYBRGreen qPCR Super-Mix-UDG with ROX (Invitrogen, Waltham, MA, USA), with the specific primers detailed in Supplementary Tables S2 and S3, respectively, in a CFX96 Touch $^{\mathrm{TM}}$ Real Time PCR Detection System (BioRad, Hercules, CA, USA), with one cycle of $95^{\circ} \mathrm{C}$ for 2 min and 40 cycles consisting of $95^{\circ} \mathrm{C}$ for $30 \mathrm{~s}$ and $60^{\circ} \mathrm{C}$ for $30 \mathrm{~s}$ or one cycle of $95^{\circ} \mathrm{C}$ for $3 \mathrm{~min}$ or 60 cycles consisting of $95^{\circ} \mathrm{C}$ for $20 \mathrm{~s}, 53{ }^{\circ} \mathrm{C}$ for $90 \mathrm{~s}$ and $50^{\circ} \mathrm{C}$ for $30 \mathrm{~s}$, respectively. Expression values were normalized to UBQ10 or $18 \mathrm{~S}$ genes, respectively, using the $2^{-\mathrm{ddCt}}$ method [81].

\subsection{Statistical Analysis}

The statistical analysis of the relative gene expression was performed by the pair wise fixed reallocation randomization test $(p$-value $<0.05)$ [82]. For the remaining parameters, the analysis was carried out using one or two-way ANOVA with the means compared by the Duncan test $(p$-value < 0.05) using the InfoStat software, version 2010 [83].

Supplementary Materials: The following are available online at https: / www.mdpi.com/article/ $10.3390 /$ ijms22179547/s1.

Author Contributions: Conceptualization, P.H. and L.P.; investigation, A.P.-G. and A.A.-B.; writingoriginal draft preparation, A.P.-G. and L.P.; review and editing, P.H. and L.P. All authors have read and agreed to the published version of the manuscript.

Funding: This research was funded by the Spanish Ministry of Economy and Competitiveness, and by FEDER funds from the European Union, grant number BIO2017-87828-C2-1-P and PID2020116940RB-I00.

Institutional Review Board Statement: Not applicable.

Informed Consent Statement: Not applicable.

Data Availability Statement: Not applicable.

Acknowledgments: We acknowledge the SCSIE (Universitat de València) for the ICP-MS service.

Conflicts of Interest: The authors declare no conflict of interest.

\section{References}

1. Marschner, H. (Ed.) Marschner's Mineral Nutrition of Higher Plants, 3rd ed.; Academic Press: San Diego, CA, USA, 2012; ISBN 9780123849052.

2. Ravet, K.; Pilon, M. Copper and iron homeostasis in plants: The challenges of oxidative stress. Antioxid. Redox Signal. 2013, 19, 919-932. [CrossRef] [PubMed]

3. Puig, S. Function and Regulation of the Plant COPT Family of High-Affinity Copper Transport Proteins. Adv. Bot. 2014, 2014, 476917. [CrossRef]

4. Peñarrubia, L.; Romero, P.; Carrió-Seguí, A.; Andrés-Bordería, A.; Moreno, J.; Sanz, A. Temporal aspects of copper homeostasis and its crosstalk with hormones. Front. Plant Sci. 2015, 6, 255-273. [CrossRef] [PubMed] 
5. Merchant, S.S.; Schmollinger, S.; Strenkert, D.; Moseley, J.L.; Blaby-Haas, C.E. From economy to luxury: Copper homeostasis in Chlamydomonas and other algae. Biochim. Biophys. Acta-Mol. Cell Res. 2020, 1867, 118822-118832. [CrossRef]

6. Hong-Hermesdorf, A.; Miethke, M.; Gallaher, S.D.; Kropat, J.; Dodani, S.C.; Chan, J.; Barupala, D.; Domaille, D.W.; Shirasaki, D.I.; Loo, J.A.; et al. Subcellular metal imaging identifies dynamic sites of $\mathrm{Cu}$ accumulation in Chlamydomonas. Nat. Chem. Biol. 2014, 10, 1034-1042, Erratum in 2015, 11, 235. [CrossRef]

7. Kropat, J.; Tottey, S.; Birkenbihl, R.P.; Depège, N.; Huijser, P.; Merchant, S.S. A regulator of nutritional copper signaling in Chlamydomonas is an SBP domain protein that recognizes the GTAC core of copper response element. Proc. Natl. Acad. Sci. USA 2005, 102, 18730-18735. [CrossRef] [PubMed]

8. Yamasaki, H.; Hayashi, M.; Fukazawa, M.; Kobayashi, Y.; Shikanai, T. SQUAMOSA promoter binding protein-like7 is a central regulator for copper homeostasis in Arabidopsis. Plant Cell 2009, 21, 347-361. [CrossRef]

9. Bernal, M.; Casero, D.; Singh, V.; Wilson, G.T.; Grande, A.; Yang, H.; Dodani, S.C.; Pellegrini, M.; Huijser, P.; Connolly, E.L.; et al. Transcriptome sequencing identifies SPL7-regulated copper acquisition genes FRO4/FRO5 and the copper dependence of iron homeostasis in Arabidopsis. Plant Cell 2012, 24, 738-761. [CrossRef]

10. Huijser, P.; Schmid, M. The control of developmental phase transitions in plants. Development 2011, 138, 4117-4129. [CrossRef]

11. Yamasaki, K.; Kigawa, T.; Seki, M.; Shinozaki, K.; Yokoyama, S. DNA-binding domains of plant-specific transcription factors: Structure, function, and evolution. Trends Plant Sci. 2013, 18, 267-276. [CrossRef]

12. Guo, A.Y.; Zhu, Q.H.; Gu, X.; Ge, S.; Yang, J.; Luo, J. Genome-wide identification and evolutionary analysis of the plant specific SBP-box transcription factor family. Gene 2008, 418, 1-8. [CrossRef]

13. Xing, S.; Salinas, M.; Höhmann, S.; Berndtgen, R.; Huijser, P. miR156-targeted and nontargeted SBP-Box transcription factors act in concert to secure male fertility in Arabidopsis. Plant Cell 2010, 22, 3935-3950. [CrossRef]

14. Rhoades, M.W.; Reinhart, B.J.; Lim, L.P.; Burge, C.B.; Bartel, B.; Bartel, D.P. Prediction of plant microRNA targets. Cell 2002, 110, 513-520. [CrossRef]

15. Schwab, R.; Palatnik, J.F.; Riester, M.; Schommer, C.; Schmid, M.; Weigel, D. Specific effects of microRNAs on the plant transcriptome. Dev. Cell 2005, 8, 517-527. [CrossRef] [PubMed]

16. $\mathrm{Wu}, \mathrm{G} . ;$ Poethig, R.S. Temporal regulation of shoot development in Arabidopsis thaliana by miRr156 and its target SPL3. Development 2006, 133, 3539-3547. [CrossRef]

17. Gandikota, M.; Birkenbihl, R.P.; Höhmann, S.; Cardon, G.H.; Saedler, H.; Huijser, P. The miRNA156/157 recognition element in the $3^{\prime}$ UTR of the Arabidopsis SBP box gene SPL3 prevents early flowering by translational inhibition in seedlings. Plant J. 2007, 49, 683-693. [CrossRef]

18. Xu, Y.; Qian, Z.; Zhou, B.; Wu, G. Age-dependent heteroblastic development of leaf hairs in Arabidopsis. New Phytol. 2019, 224, 741-748. [CrossRef]

19. Aukerman, M.J.; Sakai, H. Regulation of flowering time and floral organ identity by a microRNA and its Apetala2-like target genes. Plant Cell 2003, 15, 2730-2741. [CrossRef] [PubMed]

20. Ó'Maoiléidigh, D.S.; van Driel, A.D.; Singh, A.; Sang, Q.; Le Bec, N.; Vincent, C.; de Olalla, E.B.G.; Vayssières, A.; Branchat, M.R.; Severing, E.; et al. Systematic Analyses of the MIR172 Family Members of Arabidopsis Define Their Distinct Roles in Regulation of APETALA2 during Floral Transition. PLoS Biol. 2021, 19, e3001043. [CrossRef] [PubMed]

21. Wang, J.W.; Czech, B.; Weigel, D. miR156-Regulated SPL Transcription Factors Define an Endogenous Flowering Pathway in Arabidopsis thaliana. Cell 2009, 138, 738-749. [CrossRef]

22. Wu, G.; Park, M.Y.; Conway, S.R.; Wang, J.W.; Weigel, D.; Poethig, R.S. The Sequential Action of miR156 and miR172 Regulates Developmental Timing in Arabidopsis. Cell 2009, 138, 750-759. [CrossRef]

23. Schwarz, S.; Grande, A.V.; Bujdoso, N.; Saedler, H.; Huijser, P. The microRNA regulated SBP-box genes SPL9 and SPL15 control shoot maturation in Arabidopsis. Plant Mol. Biol. 2008, 67, 183-195. [CrossRef] [PubMed]

24. Yamaguchi, A.; Wu, M.F.; Yang, L.; Wu, G.; Poethig, R.S.; Wagner, D. The MicroRNA-Regulated SBP-Box Transcription Factor SPL3 Is a Direct Upstream Activator of LEAFY, FRUITFULL, and APETALA1. Dev. Cell 2009, 17, 268-278. [CrossRef]

25. Rubio-Somoza, I.; Weigel, D. MicroRNA networks and developmental plasticity in plants. Trends Plant Sci. 2011, 16, 258-264. [CrossRef]

26. Yu, N.; Niu, Q.W.; Ng, K.H.; Chua, N.H. The role of miR156/SPLs modules in Arabidopsis lateral root development. Plant J. 2015, 83, 673-685. [CrossRef]

27. Xu, M.; Hu, T.; Zhao, J.; Park, M.Y.; Earley, K.W.; Wu, G.; Yang, L.; Poethig, R.S. Developmental Functions of miR156-Regulated SQUAMOSA PROMOTER BINDING PROTEIN-LIKE (SPL) Genes in Arabidopsis thaliana. PLoS Genet. 2016, 12, 1-29. [CrossRef] [PubMed]

28. He, J.; Xu, M.; Willmann, M.R.; McCormick, K.; Hu, T.; Yang, L.; Starker, C.G.; Voytas, D.F.; Meyers, B.C.; Poethig, R.S. Thresholddependent repression of SPL gene expression by miR156/miR157 controls vegetative phase change in Arabidopsis thaliana. PLoS Genet. 2018, 14, e1007337. [CrossRef] [PubMed]

29. Jeyakumar, J.M.J.; Ali, A.; Wang, W.M.; Thiruvengadam, M. Characterizing the role of the miR156-SPL network in plant development and stress response. Plants 2020, 9, 1206. [CrossRef]

30. Zheng, C.; Ye, M.; Sang, M.; Wu, R. A regulatory network for mir156-spl module in arabidopsis thaliana. Int. J. Mol. Sci. 2019, 20, 6166. [CrossRef] 
31. Cardon, G.; Höhmann, S.; Klein, J.; Nettesheim, K.; Saedler, H.; Huijser, P. Molecular characterisation of the Arabidopsis SBP-box genes. Gene 1999, 237, 91-104. [CrossRef]

32. Birkenbihl, R.P.; Jach, G.; Saedler, H.; Huijser, P. Functional dissection of the plant-specific SBP-domain: Overlap of the DNAbinding and nuclear localization domains. J. Mol. Biol. 2005, 352, 585-596. [CrossRef]

33. Jana, T.; Brodsky, S.; Barkai, N. Speed-Specificity Trade-Offs in the Transcription Factors Search for Their Genomic Binding Sites. Trends Genet. 2021, 37, 421-432. [CrossRef] [PubMed]

34. Schulten, A.; Bytomski, L.; Quintana, J.; Bernal, M.; Krämer, U. Do Arabidopsis Squamosa promoter binding Protein-Like genes act together in plant acclimation to copper or zinc deficiency? Plant Direct 2019, 3, e00150. [CrossRef]

35. Chao, L.M.; Liu, Y.Q.; Chen, D.Y.; Xue, X.Y.; Mao, Y.B.; Chen, X.Y. Arabidopsis Transcription Factors SPL1 and SPL12 Confer Plant Thermotolerance at Reproductive Stage. Mol. Plant 2017, 10, 735-748. [CrossRef] [PubMed]

36. Stone, J.M.; Liang, X.; Nekl, E.R.; Stiers, J.J. Arabidopsis AtSPL14, a plant-specific SBP-domain transcription factor, participates in plant development and sensitivity to fumonisin B1. Plant J. 2005, 41, 744-754. [CrossRef]

37. Yamasaki, H.; Abdel-Ghany, S.E.; Cohu, C.M.; Kobayashi, Y.; Shikanai, T.; Pilon, M. Regulation of copper homeostasis by micro-RNA in Arabidopsis. J. Biol. Chem. 2007, 282, 16369-16378. [CrossRef]

38. Andrés-Colás, N.; Perea-García, A.; Mayo De Andrés, S.; Garcia-Molina, A.; Dorcey, E.; Rodríguez-Navarro, S.; Pérez-Amador, M.A.; Puig, S.; Peñarrubia, L. Comparison of global responses to mild deficiency and excess copper levels in Arabidopsis seedlings. Metallomics 2013, 5, 1234-1246. [CrossRef] [PubMed]

39. Pilon, M.; Cohu, C.M.; Ravet, K.; Abdel-Ghany, S.E.; Gaymard, F. Essential transition metal homeostasis in plants. Curr. Opin. Plant Biol. 2009, 12, 347-357. [CrossRef]

40. Burkhead, J.L.; Gogolin Reynolds, K.A.; Abdel-Ghany, S.E.; Cohu, C.M.; Pilon, M. Copper homeostasis. New Phytol. 2009, 182, 799-816. [CrossRef]

41. Jones-Rhoades, M.W.; Bartel, D.P. Computational identification of plant microRNAs and their targets, including a stress-induced miRNA. Mol. Cell 2004, 14, 787-799. [CrossRef]

42. Sunkar, R.; Zhu, J.K. Novel and stress-regulated microRNAs and other small RNAs from. Arab. Plant Cell 2004, 16, 2019. [CrossRef]

43. Beauclair, L.; Yu, A.; Bouché, N. MicroRNA-directed cleavage and translational repression of the copper chaperone for superoxide dismutase mRNA in Arabidopsis. Plant J. 2010, 62, 454-462. [CrossRef]

44. Abdel-Ghany, S.E.; Pilon, M. MicroRNA-mediated systemic down-regulation of copper protein expression in response to low copper availability in Arabidopsis. J. Biol. Chem. 2008, 283, 15932-15945. [CrossRef] [PubMed]

45. Sunkar, R.; Chinnusamy, V.; Zhu, J.; Zhu, J.K. Small RNAs as big players in plant abiotic stress responses and nutrient deprivation. Trends Plant Sci. 2007, 12, 301-309. [CrossRef]

46. Zhu, C.; Ding, Y.; Liu, H. MiR398 and plant stress responses. Physiol. Plant. 2011, 143, 1-9. [CrossRef] [PubMed]

47. Mittler, R. Oxidative stress, antioxidants and stress tolerance. Trends Plant Sci. 2002, 7, 405-410. [CrossRef]

48. Jagadeeswaran, G.; Zheng, Y.; Li, Y.F.; Shukla, L.I.; Matts, J.; Hoyt, P.; MacMil, S.L.; Wiley, G.B.; Roe, B.A.; Zhang, W.; et al. Cloning and characterization of small RNAs from Medicago truncatula reveals four novel legume-specific microRNA families. New Phytol. 2009, 184, 85-98. [CrossRef] [PubMed]

49. Siré, C.; Moreno, A.B.; Garcia-Chapa, M.; López-Moya, J.J.; San Segundo, B. Diurnal oscillation in the accumulation of Arabidopsis microRNAs, miR167, miR168, miR171 and miR398. FEBS Lett. 2009, 583, 1039-1044. [CrossRef]

50. Abdel-Ghany, S.E.; Müller-Moulé, P.; Niyogi, K.K.; Pilon, M.; Shikanai, T. Two P-type ATPases are required for copper delivery in Arabidopsis thaliana chloroplasts. Plant Cell 2005, 17, 1233-1251. [CrossRef]

51. Zhao, Q.; Nakashima, J.; Chen, F.; Yin, Y.; Fu, C.; Yun, J.; Shao, H.; Wang, X.; Wang, Z.Y.; Dixon, R.A. LACCASE is necessary and nonredundant with PEROXIDASE for lignin polymerization during vascular development in Arabidopsis. Plant Cell 2013, 25, 3976-3987. [CrossRef]

52. Schuetz, M.; Benske, A.; Smith, R.A.; Watanabe, Y.; Tobimatsu, Y.; Ralph, J.; Demura, T.; Ellis, B.; Samuels, A.L. Laccases direct lignification in the discrete secondary cell wall domains of protoxylem. Plant Physiol. 2014, 166, 798-807. [CrossRef] [PubMed]

53. Ma, C.; Burd, S.; Lers, A. MiR408 is involved in abiotic stress responses in Arabidopsis. Plant J. 2015, 84, 169-187. [CrossRef] [PubMed]

54. Carrió-Seguí, À.; Ruiz-Rivero, O.; Villamayor-Belinchón, L.; Puig, S.; Perea-García, A.; Peñarrubia, L. The altered expression of Microrna408 influences the arabidopsis response to iron deficiency. Front. Plant Sci. 2019, 10, 324-337. [CrossRef]

55. Pan, J.; Huang, D.; Guo, Z.; Kuang, Z.; Zhang, H.; Xie, X.; Ma, Z.; Gao, S.; Lerdau, M.T.; Chu, C.; et al. Overexpression of microRNA408 enhances photosynthesis, growth, and seed yield in diverse plants. J. Integr. Plant Biol. 2018, 60, 323-340. [CrossRef]

56. Song, X.; Li, Y.; Cao, X.; Qi, Y. MicroRNAs and their regulatory roles in plant-environment interactions. Annu. Rev. Plant Biol. 2019, 70, 489-525. [CrossRef] [PubMed]

57. Zhang, H.; Zhao, X.; Li, J.; Cai, H.; Deng, X.W.; Li, L. MicroRNA408 is critical for the HY5-SPl7 gene network that mediates the coordinated response to light and copper. Plant Cell 2014, 26, 4933-4953. [CrossRef]

58. Axtell, M.J.; Bowman, J.L. Evolution of plant microRNAs and their targets. Trends Plant Sci. 2008, 13, 343-349. [CrossRef]

59. Kozomara, A.; Griffiths-Jones, S. MiRBase: Integrating microRNA annotation and deep-sequencing data. Nucleic Acids Res. 2011, 39, 152-157. [CrossRef] 
60. Cuperus, J.T.; Fahlgren, N.; Carrington, J.C. Evolution and functional diversification of MIRNA genes. Plant Cell 2011, 23, 431-442. [CrossRef] [PubMed]

61. Shahbaz, M.; Pilon, M. Conserved Cu-microRNAs in Arabidopsis thaliana function in copper economy under deficiency. Plants 2019, 8, 141. [CrossRef] [PubMed]

62. Andrés-Colás, N.; Perea-García, A.; Puig, S.; Peñarrubia, L. Deregulated copper transport affects Arabidopsis development especially in the absence of environmental cycles. Plant Physiol. 2010, 153, 170-184. [CrossRef]

63. Cho, S.H.; Coruh, C.; Axtell, M.J. miR156 and miR390 regulate tasiRNA accumulation and developmental timing in physcomitrella patens. Plant Cell 2013, 24, 4837-4849. [CrossRef]

64. Perea-García, A.; Garcia-Molina, A.; Andrés-Colás, N.; Vera-Sirera, F.; Pérez-Amador, M.A.; Puig, S.; Peñarrubia, L. Arabidopsis copper transport protein COPT2 participates in the cross talk between iron deficiency responses and low-phosphate signaling. Plant Physiol. 2013, 162, 180-194. [CrossRef]

65. Kastoori Ramamurthy, R.; Xiang, Q.; Hsieh, E.J.; Liu, K.; Zhang, C.; Waters, B.M. New aspects of iron-copper crosstalk uncovered by transcriptomic characterization of Col-0 and the copper uptake mutant: Spl7 in Arabidopsis thaliana. Metallomics 2018, 10, 1824-1840. [CrossRef] [PubMed]

66. Sommer, F.; Kropat, J.; Malasarn, D.; Grossoehme, N.E.; Chen, X.; Giedroc, D.P.; Merchant, S.S. The CRR1 nutritional copper sensor in Chlamydomonas contains two distinct metal-responsive domains. Plant Cell 2010, 22, 4098-4113. [CrossRef]

67. Cardon, G.H.; Höhmann, S.; Nettesheim, K.; Saedler, H.; Huijser, P. Functional analysis of the Arabidopsis thaliana SBP-box gene SPL3: A novel gene involved in the floral transition. Plant J. 1997, 12, 367-377. [CrossRef] [PubMed]

68. Jung, J.H.; Seo, P.J.; Kang, S.K.; Park, C.M. miR172 signals are incorporated into the miR156 signaling pathway at the SPL3/4/5 genes in Arabidopsis developmental transitions. Plant Mol. Biol. 2011, 76, 35-45. [CrossRef] [PubMed]

69. Yan, J.; Chia, J.C.; Sheng, H.; Jung, H.I.; Zavodna, T.O.; Zhang, L.; Huang, R.; Jiao, C.; Craft, E.J.; Fei, Z.; et al. Arabidopsis pollen fertility requires the transcription factors CITF1 and SPL7 that regulate copper delivery to anthers and jasmonic acid synthesis. Plant Cell 2017, 29, 3012-3029. [CrossRef]

70. Busoms, S.; Terés, J.; Yant, L.; Poschenrieder, C.; Salt, D.E. Adaptation to coastal soils through pleiotropic boosting of ion and stress hormone concentrations in wild Arabidopsis thaliana. New Phytol. 2021. [CrossRef]

71. Perea-García, A.; Puig, S.; Peñarrubia, L. The role of posttranscriptional modulators of metalloproteins in the response to metal deficiencies. J. Exp. Bot. in press.

72. Pilon, M. The copper microRNAs. New Phytol. 2017, 213, 1030-1035. [CrossRef]

73. Stief, A.; Altmann, S.; Hoffmann, K.; Pant, B.D.; Scheible, W.R.; Bäurle, I. Arabidopsis miR156 regulates tolerance to recurring environmental stress through SPL transcription factors. Plant Cell 2014, 26, 1792-1807. [CrossRef]

74. Cui, L.G.; Shan, J.X.; Shi, M.; Gao, J.P.; Lin, H.X. The miR156-SPL9-DFR pathway coordinates the relationship between development and abiotic stress tolerance in plants. Plant J. 2014, 80, 1108-1117. [CrossRef] [PubMed]

75. Visentin, I.; Pagliarani, C.; Deva, E.; Caracci, A.; Turečková, V.; Novák, O.; Lovisolo, C.; Schubert, A.; Cardinale, F. A novel strigolactone-miR156 module controls stomatal behaviour during drought recovery. Plant Cell Environ. 2020, 43, 1613-1624. [CrossRef]

76. Andrés-Colás, N.; Sancenón, V.; Rodríguez-Navarro, S.; Mayo, S.; Thiele, D.J.; Ecker, J.R.; Puig, S.; Peñarrubia, L. The Arabidopsis heavy metal P-type ATPase HMA5 interacts with metallochaperones and functions in copper detoxification of roots. Plant J. 2006, 45, 225-236. [CrossRef]

77. Hermans, C.; Vuylsteke, M.; Coppens, F.; Craciun, A.; Inzé, D.; Verbruggen, N. Early transcriptomic changes induced by magnesium deficiency in Arabidopsis thaliana reveal the alteration of circadian clock gene expression in roots and the triggering of abscisic acid-responsive genes. New Phytol. 2010, 187, 119-131. [CrossRef]

78. Carrió-Seguí, A.; Garcia-Molina, A.; Sanz, A.; Peñarrubia, L. Defective copper transport in the copt5 mutant affects cadmium tolerance. Plant Cell Physiol. 2015, 56, 442-454. [CrossRef] [PubMed]

79. Jefferson, R.A.; Kavanagh, T.A.; Bevan, M.W. GUS fusions: Beta-glucuronidase as a sensitive and versatile gene fusion marker in higher plants. EMBO J. 1987, 6, 3901-3907. [CrossRef]

80. Yang, H.; Schmuke, J.J.; Flagg, L.M.; Roberts, J.K.; Allen, E.M.; Ivashuta, S.; Gilbertson, L.A.; Armstrong, T.A.; Christian, A.T. A novel real-time polymerase chain reaction method for high throughput quantification of small regulatory RNAs. Plant Biotechnol. J. 2009, 7, 621-630. [CrossRef]

81. Livak, K.J.; Schmittgen, T.D. Analysis of relative gene expression data using real-time quantitative PCR and the 2- $\Delta \Delta C T$ method. Methods 2001, 25, 402-408. [CrossRef] [PubMed]

82. Pfaffl, M.W. Relative expression software tool (REST(C)) for group-wise comparison and statistical analysis of relative expression results in real-time PCR. Nucleic Acids Res. 2002, 30, e36. [CrossRef] [PubMed]

83. Di Rienzo, J.A.; Casanoves, F.; Balzarini, M.G.; Gonzalez, L.; Tablada, M.; Robledo, C.W. InfoStat. 2011. Available online: www.infostat.com. 